Romera Tébar, Cristina. Las minas de Hellín (Albacete): huellas del pasado en un espacio olvidado. GeoGraphos. [En línea]. Alicante: Grupo Interdisciplinario de Estudios Críticos y de América Latina (GIECRYAL) de la Universidad de Alicante, 13 de febrero de 2014, vol. 5, no 63, p. 167-205 [ISSN: 2173-1276]. [DOI: 10.14198/GEOGRA2014.5.63].

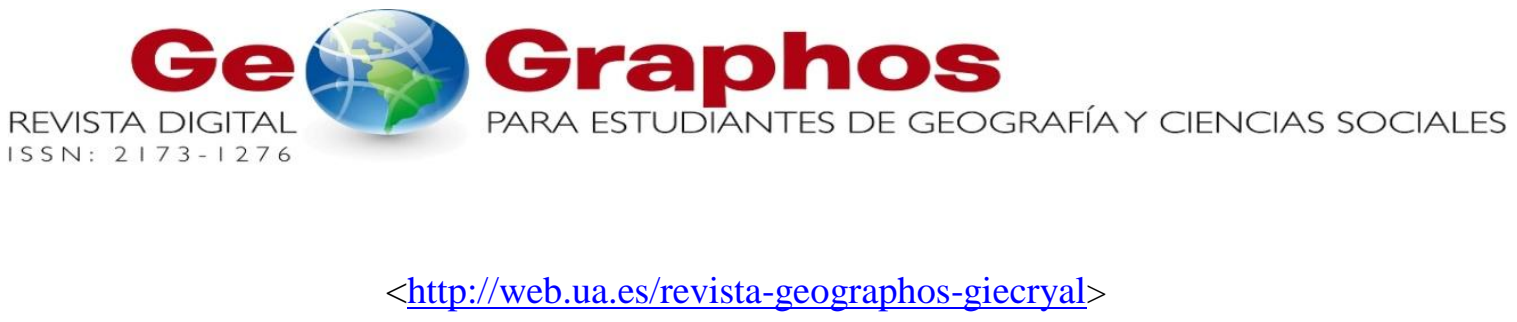

Vol. 5. $\mathrm{N}^{\circ} 63$

Año 2014

\title{
LAS MINAS DE HELLÍN (ALBACETE): HUELLAS DEL PASADO EN UN ESPACIO OLVIDADO
}

\author{
Cristina Romera Tébar \\ Grado en Geografía y Ordenación del Territorio \\ Facultad de Filosofía y Letras. Universidad de Alicante (Alicante, España) \\ Correo electrónico: crt8@alu.ua.es
}

Recibido: 23 de julio de 2013. Devuelto para revisión: 9 de septiembre de 2013.

Aceptado: 13 de febrero de 2013
"Cásate conmigo niña que soy minero de azufre, que gano siete reales y $\mathrm{pa}^{\prime}$ vivir ya nos cubre" Isabel Serrano. Dichos, coplas y versos tópicos de La Mancha y de la provincia de Albacete. Albacete: Instituto de Estudios Albacetenses “Don Juan Manuel”, 2000, Serie 1, $n^{o}$ 122, p. 244.

\section{RESUMEN}

Tras el desarrollo de la industria minera del alcrebite en la pedanía de Las Minas de Hellín sobre todo en los siglos XVIII-XIX, este espacio rural ha quedado en la actualidad totalmente abandonado fruto de la quiebra de su explotación. A pesar de su 
devastador cierre el poblado minero, aunque muy deteriorado, se conserva en nuestros días encerrando vestigios de un pasado que logró posicionar a esta zona minera como la primera a nivel nacional. Ha sido la propia configuración de este espacio situado entre los ríos Mundo y Segura la que lo ha dotado como uno de los emplazamientos más singulares a la par que desconocido, generando una gran carencia de información acerca del mismo que sin duda está quedando compensada mediante los grandes pleitos sociales que hoy ocupan un importante apartado en su historia.

Palabras clave: Minas de Hellín, alcrebite, siglos XVIII-XIX, cursos fluviales, singularidad.

\title{
HELLIN'S MINES (ALBACETE). TRACES OF THE PAST IN A FORGOTTEN SPACE
}

\begin{abstract}
After the development of the mining industry in Hellin's Mines especially in the centuries XVIII-XIX, this rural space has stayed at present totally left fruit of the bankruptcy of its exploitation. In spite of its devastating closing the mining settlement, thought very damaged, it remains nowadays enclosing vestiges of a past that managed to position to this mining zone as first national. It has been the own configuration of this space placed between the rivers Mundo and Segura the one that has endowed as one of the most singular emplacements at par that not known, generating a great lack of information brings over of the same one that undoubtedly is remaining compensated by means of the big social lawsuits that today occupy an important paragraph.
\end{abstract}

Keywords: Hellin's Mines, Sulphur, Centuries XVIII-XIX, Fluvial Courses, Singularity.

\section{LAS MINAS DE HELLÍN (ALBACETE). VESTÍGIOS DO PASSADO EM UM ESPAÇO ESQUECIDO}

\section{RESUMO}

Depois de desenvolver a indústria de mineração alcrebite na aldeia de Las Minas de Hellín especialmente no século XVIII, a área rural foi agora totalmente abandonada resultado da falência de sua exploração. Apesar de sua devastadora perto da cidade mineira, embora muito deteriorado, abrangendo hoje conserva vestígios de um passado que foi capaz de posicionar esta área de mineração como a primeira em todo o país. Foi a configuração do espaço entre Mundo e rios Segura que lhe forneceu um dos locais mais originais, ao mesmo tempo desconhecido, gerando uma grande falta de informação sobre o assunto, que é, certamente, ser compensado pela grandes processos sociais ocupam agora uma parte importante de sua história. 
Palavras-chave: Minas de Hellín, enxofre, idade XVIII-XIX, cursos de água, singularidade.

\section{INTRODUCCIÓN}

La pedanía de las Minas, situada al sur de Hellín sobre las aguas del río Segura, se asienta sobre una antigua zona de explotación de minas de azufre que tal y como indica dio nombre a este lugar, considerada en tiempos remotos como una de las zonas de mayor riqueza en lo referido a la obtención y producción de azufre nativo, logrando posicionarse como el gran líder de dicha producción en la Europa sudoccidental. Sin embargo, la construcción y configuración de este espacio no fue tarea sencilla puesto que la propiedad ha pasado repetidas veces por numerosas manos, tanto del ámbito público como del privado, que buscaban obtener grandes beneficios de estas tierras.

Quizá y como numerosos autores recalcan, al contrario que en otros lugares, la facilidad proporcionada por el terreno sobre el que se asentaba este coto minero para poder extraer sus recursos, fue el principal factor que desencadenó la decadencia de esta zona, que en sus tiempos más espléndidos llegó a contar con una población de más de 2000 habitantes, adecuada a las reducidas dimensiones del lugar, pero bien dotada en cuanto a servicios ya que contaba con farmacias, cines, teatros, lugares de ocio, médicos... Todo ello no fue más que el reflejo de la gran prosperidad que se logró alcanzar en este coto, sobre todo a finales del siglo XIX y principios del XX y que hoy se ve totalmente contrapuesta mediante un paisaje que muestra minas abandonadas, casas derruidas, gran pobreza entre los edificios que todavía se conservan, falta de medios, destrucción de grandes infraestructuras, etc.

Así pues y a pesar del prometedor panorama que se reflejaba en este espacio, el abandono del mismo vino propiciado por diversas causas como fueron la falta de innovaciones tecnológicas y de capitales para poder mantener las minas, por las sucesivas disputas que se han dado por su tenencia, por la tradicional forma de explotación de las minas, pero sobre todo por la posición de esta zona entre los ríos Mundo y Segura, que debido a su paso por Las Minas y en especial en época de verano propicia grandes plagas de mosquitos que en su momento obligaron a reducir las jornadas de trabajo en la mina a los meses de invierno por las condiciones insalubres en las que se trabajaba.

Es de este modo como se aprecia que si bien el terreno sobre el que se asienta esta pedanía fue un factor que propició la creación de las minas debido a las facilidades que propiciaba en cuanto a su extracción, fue a la par el detonante del abandono del lugar debido a la confluencia de los dos ríos que se han mencionado y que hacían insostenibles las condiciones de vida en determinadas estaciones del año. 
Por lo tanto, esta zona de minas que abarcó en su máximo apogeo una superficie de 135 kilómetros cuadrados en los se explotaban 17 vetas y que en numerosas ocasiones se ha definido como "minas únicas en España y de la mejor calidad de cuantas se hallan descubierto" enmarcan una situación compleja y difícil de analizar que se abarcará en el presente trabajo, en donde tanto factores sociales, culturales y económicos han condicionado el devenir de este espacio que muestra como los vaivenes de la historia pueden cambiar radicalmente el curso de toda una sociedad.

Figura 1. Mapa de situación de la pedanía Minas de Hellín

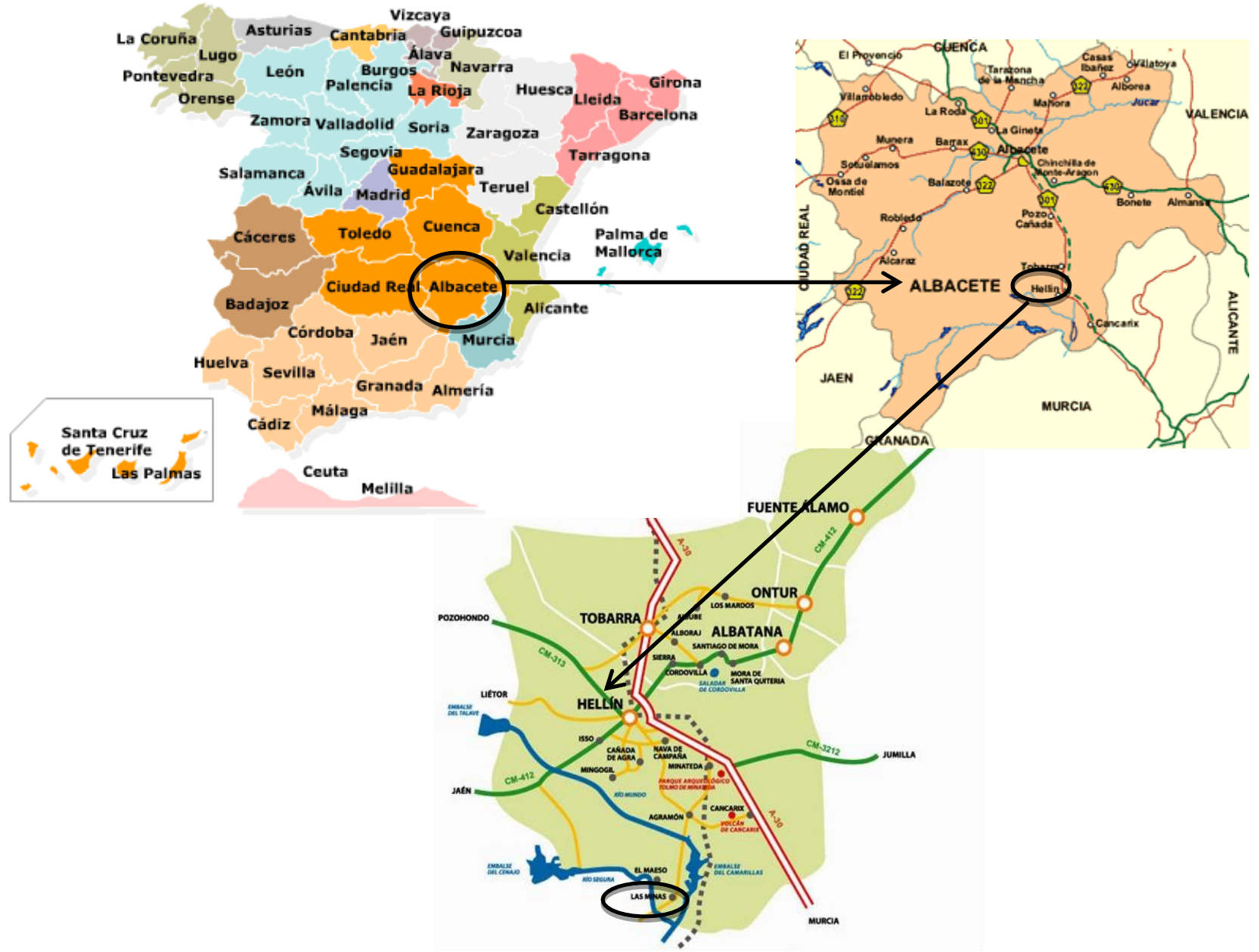

Fuente: Imágenes de Google 2013. Elaboración propia.

\section{COMPOSICIÓN GEOLÓGICA DEL ESPACIO ANALIZADO}

La dualidad que siempre ha existido en este territorio entre el avance y la regresión ha propiciado que sobre esta localidad representada siempre con un peculiar aspecto "pueblerino" solo hayan actuado una serie de compañías nacionales que han luchado por sacar el mayor rendimiento posible a las minas, sin preocupación alguna por la 
preservación del medio que a largo plazo ha resultado tal y como se analizará, insostenible. Es por ello que este paraje se ha convertido a través del tiempo en el símbolo de la España dual del siglo XIX y en la actualidad ha pasado a ser el fruto de la salvaje expoliación que ha acometido la propia riqueza natural del lugar.

Teniendo en cuenta la importancia que este espacio en sí mismo encierra se tendrían que considerar dos aspectos fundamentales que son los que explican la singularidad del lugar; por un lado la adscripción de esta pedanía al sustrato histórico-cultural del sudeste peninsular, y por otro no menos importante el secular aislamiento del área provocado por el propio relieve con el consiguiente carácter periférico de la misma. Es la posición entre dos ríos y diversas sierras la que ha provocado durante el paso del tiempo que el acceso a este remoto lugar nunca fuera fácil, obstáculo que se vio totalmente solventado con el descubrimiento del azufre ya que provocó el asentamiento y el enclavamiento de una población minera que buscaba la obtención de un gran beneficio y potencial de la zona.

Profundizando más sobre los recursos que ofrece este territorio, el mismo se encuentra caracterizado por la alternancia de zonas de llanuras como las cañadas y hoyas en donde se asentó el pueblo de Las Minas, además de por diversas elevaciones serranas de poca altura con picachos y cabezos en donde están enclavadas las minas de azufre. Ahora bien, si esta comarca está caracterizada por ser una "isla" al respecto de Hellín que es el municipio al que pertenece, es por la separación que tiene conforme al mismo a través de la existencia de la sierra de los Donceles que se extiende desde el noroeste hacia el sureste en el conjunto de las cordilleras béticas.

Junto con estas consideraciones previas también cabe destacar el conjunto de materiales geológicos que componen esta zona para así poder ver el porqué de la existencia del azufre en la misma. Así pues, los materiales geológicos de la zona son principalmente materiales de tipo secundario (cretácico al este y jurásico al oeste), formando una serie de estratos fuertemente plegados sobre una zona triásica más antigua dando lugar a la existencia de materiales plásticos. Además, aparecen otros conjuntos de sierras con materiales del terciario, sobre todo del mioceno que ofrecen un aspecto mucho más tableado debido a su composición mediante calizas, margas arenosas y areniscas.

Debido a la tan importante zona de sedimentación marina que se da en este ámbito por el paso de dos ríos, cabe hacer mención aparte de la misma, ya que en estas zonas a veces se intercalan capas de azufre con los materiales de margas endurecidas, arenas y arcillas que componen la zona de llanura o valle en Las Minas.

Fue en definitiva la existencia de estos dos ríos con sus cuencas correspondientes la que propició el aislamiento de esta pedanía entre ambos cursos, dando lugar a una zona más bien deprimida en donde aparecen elevaciones pero de escasa altura y que componen el conjunto del poblado minero con sus respectivas explotaciones. 
Por último en lo que respecta a los materiales que componen este lugar, en el ámbito estratigráfico se pueden definir básicamente dos unidades: una primera unidad en la que hay margas arcillosas blancas en donde localmente encontramos niveles de lignito y azufre, entre los 150 y los 200 metros, y otro estrato formado por margas y calizas dolomíticas y tableadas que ocasionalmente se intercalan con algunos niveles arenosos pero en mayores alturas.

Además de ello, en algunas zonas se ha localizado desde tiempos remotos la existencia de actividad volcánica que se relaciona con la presencia de un cerro denominada de las Cabras entre la zona de Cancarix y Jumilla que ha terminado por complicar todavía más la composición de este espacio.

Debido a la composición y el aprovechamiento que se han dado, en la actualidad el paisaje que deja entrever este terreno es de un color blanquecino con escasa vegetación debido a la gran actividad de extracción del azufre que se dio y que derivó en la tala de los montes para poder obtener combustible para los hornos, además de la creación de grandes montañas de desechos producidos por la industria del azufre, todo ello durante un período de más de 400 años.

Han sido la historia y el paso del tiempo los factores que han traído hasta nuestros días los restos derruidos de una actividad sobre la que se dibujaba un futuro muy próspero, pero que ahora enseña la cara desolada del abandono de un lugar en el que se encuentran minas totalmente abandonadas y maltrechas, restos de la línea de un ferrocarril que se proclamó como la salvación al hundimiento de esta industria, hornos cilíndricos oxidados, infraestructuras obsoletas y un gran conjunto de casas-cueva totalmente hundidas entre las montañas, fiel reflejo de las duras condiciones de vida que se tenía en esta zona además de la mala calidad sanitaria que se dio en el inicio de la construcción de un paraje que hoy es el vivo retrato del olvido, fruto del fracaso de un proceso industrializador.

\section{HISTORIA Y EVOLUCIÓN DE LAS MINAS DE AZUFRE: COTO MINERO DE HELLÍN}

\section{Tradición minera}

Situada a unos 20 kilómetros al sur de Hellín (Albacete) y a 396 metros de altura, con una tradición minera de más de 400 años, aparece la pedanía de Las Minas totalmente dibujada por el paso del río Segura. Esta comarca debe su nombre a la existencia de un recurso mineral como es el azufre, del cual se obtienen datos de explotación desde época romana. Este recurso se encontraba oculto en el subsuelo de estas tierras de donde continuamente y de una manera totalmente espontánea e improvista se iba extrayendo.

Desde época romana su explotación ha ido creciendo en importancia, ya que de funcionar como la mera herramienta fundamental de alumbramiento en época romana, 
en donde se han encontrado numerosos vestigios de los utensilios utilizados para dicho alumbramiento en diversas galerías, pasó a crecer en importancia entrada la Edad Media por la utilización del mismo como pólvora durante las sucesivas guerras que se dieron, siendo en esta época donde tuvieron lugar las mayores disputas por la tenencia de estas tierras. Finalmente los mayores frutos y la mayor productividad de este material se obtuvieron de la mano de la industrialización en el siglo XIX-XX en donde el aprovechamiento del azufre se convirtió en el principal y más importante elemento de la industria química.

Ahora bien, es importante conocer cuáles son los antecedentes históricos que tiene esta explotación minera para poder entender que tan grande es la importancia que la misma viene dando desde épocas remotas. Las primeras constataciones de la existencia del azufre de esta mina las encontramos en los textos del geógrafo musulmán Az-Zuhri ${ }^{1}$ en el año 1154 en donde dicho autor a través de su recorrido por las vegas del río Segura desde su nacimiento hasta la vega de Cieza elaboró varios textos en los que mencionaba la existencia de zonas de azufre que describió de la siguiente manera:

"En cuanto al río llamado Tandra ïr o Tandrabir, que es el que llega a la ciudad de Murcia, este desciende hasta el lugar llamado Pajares, donde recibe el aporte del río mundo. En esta confluencia hay un yacimiento de azufre rojo, mineral que no se encuentra en ningún otro lugar de la tierra habitada. Se exporta a todos los países del mundo: Iraq, Yemen, Siria...

Desde este punto hasta la ciudad de Murcia hay unas 12 parasangas (unos $66 \mathrm{~km}$ ). Sigue el río su curso y recibe a continuación las aguas del río de Calasparra: entra después en una angosta garganta, conocida como "el estrecho de la fuente negra". La garganta y la fuente son una de las maravillas del mundo. Creó dios aquel desfiladero partiendo en dos una montaña de mármol rojo. La hendidura está constituida, a derecha e izquierda, por dos paredes, cada una de las cuales tiene cincuenta brazas de altura. Su longitud es de cuatro parasangas. Su parte más ancha mide una marya, y su parte más angosta un cuarto de marya. Allí no penetra el sol sino cuando está en el signo de Géminis (es decir: cuando el día es más largo)”.

Hasta esta época no se tenían más que los datos recogidos a través de estos textos sobre la existencia de las minas de azufre, ya que es a partir del siglo XV-XVI cuando comienzan a aparecer los datos más fidedignos sobre el trabajo y la explotación que se estaban realizando en estas propiedades. Esto es debido a que a partir de esta época el interés por la tenencia y la explotación del azufre como ya hemos mencionado anteriormente comienza a ser mucho más importante y la propiedad de las minas va

\footnotetext{
${ }^{1}$ Textos recopilados de Az-Zuhri durante sus viajes por la provincia murciana y alrededores. Carmona González, Alfonso. El noroeste murciano en época árabe. Miscelánea Medieval Murciana. Revista Miscelánea Medieval Murcia. 1998, n²1-22, p. 59-70.
} 
cambiando sucesivas veces de manos, con lo que aunque de manera confusa, se comienzan a tener mayores datos sobre las actividades que se realizan en dicha zona.

Si bien, lo más interesante de todo esto es que el descubrimiento posterior a la época romana de estas minas fue un hecho totalmente fortuito, ya durante la quema de rastrojos en una zona aledaña cuando el fuego se extendió más de la cuenta y llegó a esta zona comenzó a desprender un olor muy fuerte a azufre, el cual se encontraba en la parte subterránea de estas tierras y por lo tanto no había sido conocido con posteridad a los romanos.

Por lo tanto, la creación de este lugar parte de una muy larga tradición sulfurosa que marcó el inicio de una explotación minera muy poco conocida en el panorama nacional pero que merece ser considerada como una de las más importantes por hechos que posteriormente se explicarán en los diferentes apartados.

\section{Comienzos de la explotación minera y primeros resultados}

El conjunto arqueológico de las minas de azufre de Hellín se extienden en la gran cuenca terciaria que abarca desde la denominada sierra de los Donceles hasta los picos de Hellín y la sierra de las Cabras. Todo el conjunto de montañas presenta formas bastante irregulares en las que se entremezclan espacios de grandes llanuras con pequeñas elevaciones y ondulaciones, mientras que en otros tramos del conjunto aparecen profundas cañadas labradas por la acción del agua que conforman un paisaje muy variado y característico de la zona.

Para entender bien el porqué de los comienzos de esta explotación minera antes cabría profundizar un poco más en la composición y distribución de la misma para así relacionar el sistema de explotación que se daba en la zona. En lo que se refiere a ese punto, el paisaje que acabamos de describir y que reflejaba el aspecto exterior de la zona estaba compuesto en su interior por un gran número de capas que se encontraban ligeramente inclinadas, con una gran estrechez y en completo paralelismo, que guardaban en su interior y en concordancia con las mismas el tan preciado azufre. Ahora bien, estas reducidas dimensiones se explicaban porque la presencia de este mineral solamente se daba en una reducida extensión en donde confluían los ríos Mundo y Segura y en algunos lugares aledaños pero muy aislados, lo que finalmente provocó el asentamiento en un espacio tan reducido y concreto del pueblo. 
Ahora bien, el mecanismo de obtención del azufre en época romana que se realizaba exclusivamente en las capas geodas y vejigas ${ }^{2}$ debido al reducido sistema de explotación de las galerías que eran muy bajas y de gran profundidad, nos mostraba como la disposición estratigráfica del lugar desde sus inicios marcó el aprovechamiento del mismo, ya que la gran profundidad de algunas capas no permitió acceder hacia dimensiones más internas de la mina.

Se puede concluir entonces que la explotación de las minas a partir de los siglos XV y XVI estaba condicionada por una serie de características del territorio que podemos resumir en:

- Una estructura interior compuesta por 16 capas de azufre.

- Un intervalo estéril que separaba entre sí cada capa de azufre.

- Grueso de capas arcillosas por encima de los azufres era de 16 a 25 metros.

- El espesor medio de la región minera era de 10,55 varas.

- Dentro del espesor el mineral ocupaba 2,03 y la capa estéril 8,52, en términos medios.

- Una riqueza de las capas que era muy variable y que por lo tanto daba grandes desigualdades.

\footnotetext{
${ }^{2}$ Las capas de geodas y vejigas de entre las 16 capas que componían la mina eran de las más fértiles y finas sobre las cuales se podía actuar con mayor facilidad para obtener el mineral de azufre. Botella y De Hornos, Federico. Descripción geológica-minera de las provincias de Murcia y Albacete. Arte Libro, edición del 4 de Diciembre de 2002. Imprenta del Colegio Nacional de Sordomudos y Ciegos MDCCCLXVIII.
} 


\section{Cuadro 1. Corte estratigráfico de la región minera de Hellín}

\begin{tabular}{|c|c|c|c|c|c|}
\hline \multirow{2}{*}{$\begin{array}{c}\text { Número de la } \\
\text { capa }\end{array}$} & \multirow{2}{*}{$\begin{array}{c}\text { Nombre de la } \\
\text { capa }\end{array}$} & \multicolumn{4}{|c|}{ Espesor } \\
\hline & & Pies & Pulgadas & Líneas & Metros \\
\hline 1 & Concha & 1 & & & 0,278 \\
\hline 2 & $\begin{array}{l}\text { Primera } \\
\text { Estéril }\end{array}$ & 4 & & & 1,114 \\
\hline 3 & Guijarrillo & & 5 a 6 & & 0,139 \\
\hline 4 & Zapillenca & & & & \\
\hline 5 & $\begin{array}{c}\text { Guijarro }(*) \\
\text { borde } \\
\text { Estéril }\end{array}$ & & $\begin{array}{l}4 \\
5\end{array}$ & & $\begin{array}{l}0,092 \\
0,116\end{array}$ \\
\hline 6 & $\begin{array}{c}\text { Guijarro }(*) \\
\text { florido } \\
\text { Estéril } \\
\end{array}$ & 5 & $\begin{array}{l}1 \\
6\end{array}$ & 6 & $\begin{array}{r}0,031 \\
1,534 \\
\end{array}$ \\
\hline 7 & $\begin{array}{c}\text { Segunda } \\
\text { Estéril }\end{array}$ & 2 & $\begin{array}{l}8 \\
6\end{array}$ & & $\begin{array}{l}0,185 \\
0,696\end{array}$ \\
\hline 8 & $\begin{array}{l}\text { Venilla } \\
\text { Estéril }\end{array}$ & & $\begin{array}{l}1 \\
8\end{array}$ & & $\begin{array}{l}0,023 \\
0,185\end{array}$ \\
\hline 9 & $\begin{array}{c}\text { Bastarda } \\
\text { Estéril }\end{array}$ & & $\begin{array}{l}2 \\
6\end{array}$ & 6 & $\begin{array}{l}0,058 \\
0,139\end{array}$ \\
\hline 10 & $\begin{array}{c}\text { Jaspeada } \\
\text { Estéril }\end{array}$ & 7 & 9 & & $\begin{array}{l}0,208 \\
1,930\end{array}$ \\
\hline 11 & $\begin{array}{l}\text { Caños } \\
\text { Estéril }\end{array}$ & & 2 & 6 & $\begin{array}{l}0,011 \\
0,460\end{array}$ \\
\hline 12 & $\begin{array}{c}\text { Piearda } \\
\text { Estéril }\end{array}$ & 2 & 6 & 3 & $\begin{array}{l}0,050 \\
0,696\end{array}$ \\
\hline 13 & $\begin{array}{l}\text { Florida } \\
\text { Estéril }\end{array}$ & & $\begin{array}{l}8 \\
5\end{array}$ & & $\begin{array}{l}0,183 \\
0,116\end{array}$ \\
\hline 14 & $\begin{array}{l}\text { Tableta } \\
\text { Estéril }\end{array}$ & & $\begin{array}{l}1 \\
8\end{array}$ & & $\begin{array}{l}0,023 \\
0,185\end{array}$ \\
\hline 15 & $\begin{array}{c}\text { Andresa } \\
\text { Estéril }\end{array}$ & 1 & $\begin{array}{l}7 \\
4 \\
\end{array}$ & & $\begin{array}{l}0,162 \\
0,371\end{array}$ \\
\hline 16 & Gatuna & 1 & & & 0,278 \\
\hline
\end{tabular}

Fuente: Federico Botella y de Hornos. Descripción geológica-minera de las provincias de Murcia y Albacete. Elaboración propia.

Tras el encuadre del terreno en donde se sitúan las Minas de Hellín, bien es cierto que cabe reseñar que estas minas tras la época romana no conocieron producción alguna (que se haya estudiado), por lo que permanecieron cerradas hasta su posterior descubrimiento. Fue a partir del siglo XV cuando la demanda de los metales comenzó a tener auge en las tierras españolas, hecho que posteriormente sería un gran potenciador de esta industria del alcrebite. Así pues, a partir del siglo XVI con la mejora y avances de la sociedad y el momento en que la minería estaba comenzando a ser el principal sustentador económico del país fue cuando se volvió a descubrir esta zona minera y comenzó lo que sería su periodo de gran bonanza. 
El día 2 de Junio de 1562 y como ya se ha explicado, Juan Sánchez de Buendía, vecino de Moratalla y Alonso de Monreal, vecino de Abarán y hermano del anterior, "descubrieron" de forma accidental y tal y como se ha mencionado anteriormente, la pedanía de las Minas de Hellín. A partir de esta fecha comenzaron una serie de trámites llevados a cabo por estos dos vecinos para tomar posesión del coto minero de azufre y así poder realizar la explotación y el laboreo del mismo. Todo este proceso quedó reflejado en un documento emitido por Don Miguel de Burgos ${ }^{3}$ en el que se dispuso que finalmente el día 6 de Noviembre de 1565, estos dos vecinos tomaron posesión de las minas de azufre ante la Contaduría Mayor, quedando iniciado así el proceso de explotación más intenso que se realizó sobre esta extensión.

HELLIN. En Madrid a 2 de Julio de 1562 se dio provisión para que el gobernador de la orden de Santiago en el partido de Caravaca y Moratalla, o su teniente, dejasen beneficio a Alonso de Monreal y Juan Sánchez de Buendía ciertos minero de alcrebite que hallaron en los términos de las Villas de Hellín y Moratalla, reino de Murcia, cobrando el derecho de que a S.M perteneciese, el cual se debía depositar por ante las dichas justicias en una persona legal, llana y abonada.

En 12 de Julio de 1564 se presentó en el consejo de la Contaduría mayor de S.M una petición de Juan Sánchez Buendía, vecino de Moratalla, manifestando que él había hallado unos alcrebitales en término y jurisdicción de la villa de Hellín, los cuales lindaban con el Bancal de los Candeles y el río de Segura abajo, hasta la junta de este y Mundo, a la dehesa de las Camarillas, y a la punta de la sierra de los pinos Donceles, delante de aquella Solana, que está a la parte de la Torre de Pajares y el río abajo de Segura hasta volver al Bancal: y dichos señores contadores la hubieron por presentada cuanto de derecho había lugar.

En 6 de noviembre de 1565 ante los señores de la Contaduría mayor de S.M. Alonso de Monreal, vecino de la villa de Abarán, hizo presentación de un registro de mina de alcrebite que había manifestado ante Juan de Valcárcel, alcalde ordinario de la villa de Hellín, signado de Ginés de Molina en doce de octubre del mismo año, cuyos mineros estaban en los términos de la dicha villa que quedan referidos en el registro anterior: $y$ los señores contadores los hubieron por registrados cuanto de derecho había lugar.

De este breve período de tiempo en el que las minas fueron propiedad privada apenas se conserva información en cuanto al sistema de aprovechamiento que se practicaba. Es por ello que tenemos que remitirnos a la fecha de 6 de mayo de 1589 , ya que es el momento en que las minas pasan a propiedad pública de la mano del rey de España Felipe $\mathrm{II}^{3}$, que es quien toma posesión de la propiedad a partir de este momento. La compra por 200.000 ducados fue el precio que pagó el rey a la entidad privada que

\footnotetext{
${ }^{3}$ Texto extraído de la publicación de Orden del Rey, a partir de Don Miguel de Burgos. Registro y relaciones generales de Minas de la Corona de Castilla. Tomo I, Ministerio de Hacienda de España, Madrid 1832
} 
anteriormente manejaba las el coto minero fue intencionada, puesto que en este momento el incremento de los conflictos bélicos propició el aumento del valor del azufre como componente estratégico para la fabricación de la pólvora.

En 8 de Mayo de 1576. Carta para que Don Francisco de Alba, que pasaba a Cartagena, averiguase el alcrebite que se había sacado en virtud de la Carta que se dio a Alonso de Monreal para beneficiarse ciertas minas de azufre en término de las referidas villas de Hellín y Moratalla, y lo que había prescindido a S.M, y en poder de quien se hallaban.

Asiento que tomó S.M con Francisco de Monreal, sobre las minas de azogue que descubrió en término de Hellín, en que le da en recompensa de ellas veinte mil ducados. 6 de Mayo de 1589. Contadurías generales, número 851.

\section{Figura 2. Mapa de situación de los criaderos de azufre tras su delimitación. Año 1591}

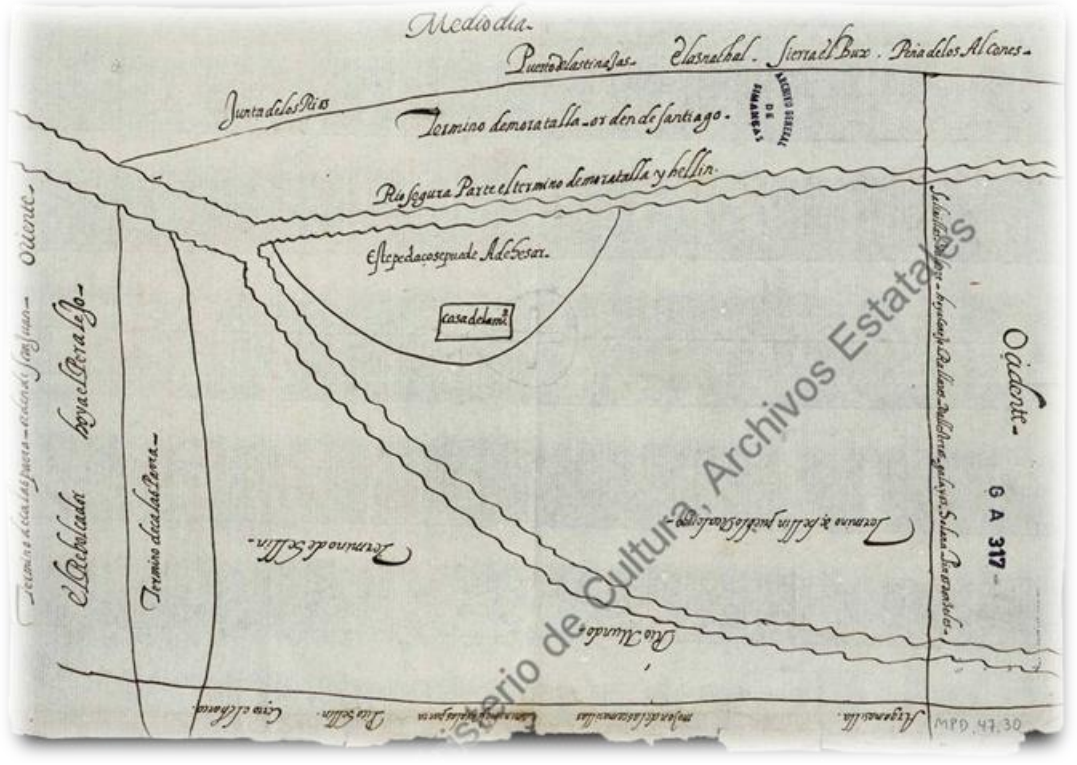

Fuente: Catálogo colectivo de la Biblioteca de Albacete.

Aunque el interés por la obtención de dicho coto minero era muy importante, la corona solamente compró el acaparamiento y el control de la producción de las minas puesto que su aprovechamiento y explotación siempre lo dejaba a cargo de manos de particulares, como en este caso fue de Francisco de Monreal, hijo de Alonso de Monreal quien a partir de 1590 cuando se hizo efectiva la venta del coto minero a la corona se quedó como administrador de la propiedad hasta el año 1610.

La importancia que la corona le dio a este espacio tras su adquisición para el Cuerpo de Artillería no tardó en despertar grandes problemas puesto que la insuficiencia en 
infraestructuras, los problemas de acceso a las minas y los problemas de fundición eran una constante en su proceso de aprovechamiento, ya que Francisco de Monreal no extendió sus hallazgos más halla de encontrar el proceso de fundición del azufre. Es por ello que tras un periodo de grave dificultad para la prosperidad de las minas, y con la finalización del contrato de Monreal, entrará como veedor, contador y administrativo, que eran las funciones que la corona delegaba la persona que contrabata, Alonso Cuellar Carrasco, que tras su muerte en 1621 delegará su cargo en su hijo, el cual poseía el mismo nombre. En este momento el rendimiento de la mina de azufre comenzó a incrementarse gracias a las mejoras en los sistemas de explotación que se obtuvieron, por lo que la zona minera fue calificada por varios autores como única en España, ya que en estos momento la pólvora se consideraba como uno de los elementos esenciales en el país y la producción de esta mina iba destinada únicamente a su fabricación.

Lo característico del sistema de explotación que además se mantuvo durante toda la vigencia de la mina, era su explotación a cielo abierto. Este sistema de explotación vino propiciado por la accesibilidad a la zona de las minas y al reducido espacio que contenía el mineral del azufre. Por otro lado, la confluencia de los dos ríos en esta zona propició el aprovechamiento del agua como elemento erosionador y de transporte, ya que mediante sistemas gravimétricos y por el discurrir del agua el caudal la misma sirvió para realizar los procesos de lavado y separado del material.

En un principio este sistema no supuso grandes problemas a la obtención del mineral puesto que era acorde con los tiempos en los que se comenzó a dar. Con la llegada de Felipe $\mathrm{V}$ al trono se dio un periodo de grandes agitaciones mediante las cuales cambió en repetidas ocasiones el sistema de manejo de las minas (en el sentido de los administradores de la misma), pero finalmente Alonso Carrasco y Cuellar tomará posesión en 1625-26 como veedor, contador y administrador de la mina, quedando todo regido bajo dominio de la Corona y llevando a cabo una serie de reformas para la mejora y ampliación de las instalaciones de la mina.

Fue la prohibición emanada por el rey a las importaciones de azufre para la mina vislumbró la gran capacidad de autosuficiencia que el coto minero de Hellín tenía para poder abastecer a la corona en su industria armamentística. Este hecho desencadenó la concepción mucho más positiva del coto minero de Hellín, que ha quedado reflejada en varios autores, como el caso del Padre Ortega quien afirmó que "estas famosas minas de azufre que son únicas en nuestra España y de la mejor calidad de cuantas se hallan descubierto son un tesoro inagotable para la corona"4.

Por lo tanto, durante los siglos XVII y XVIII la explotación de la mina seguirá bajo dominio de la corona que contrataba a diversos asentistas para el manejo directo de la explotación. Cierto es que en este periodo de constantes revulsiones y revueltas el papel

\footnotetext{
${ }^{4}$ Bellón López, Sebastián. Arqueología Industrial en Castilla - La Mancha: las minas de azufre de Hellín. Revista Añil. Centro de Estudios de Castilla-La Mancha. 2003. nº 25
} 
que los asentistas tomaban para la obtención de beneficios de las minas iba mucho más lejos del meramente estricto que le otorgaba la corona, ya que muchos de ellos comenzaron a desarrollar labores de agricultura y ganadería en las tierras llanas aledañas a la zona, por lo que alteraron sistemáticamente el modo de explotación del coto minero con la mezcla de las tres actividades: agricultura, ganadería y minería.

De todo ello surgió en estos momentos la construcción y el trazado del pueblo que se llevó a cabo mediante una gran planificación urbanística acorde con los usos de la zona, por lo que se construyeron cuadras para los animales de tiro para la mina, almacenes para los productos tanto cosechados como obtenidos de la minería, zonas residenciales... Fue precisamente con la construcción de la zona residencial y la delimitación total de la extensión cuando comenzaron a darse grandes disputas por la tenencia de la propiedad, debido al "gran futuro y prosperidad" que se reflejaban, por lo que diversas órdenes, como la de Santiago en Moratalla y la de Calasparra, municipios colindantes a la zona, se disputaron su tenencia.

El reflejo de todo este primer proceso de la construcción del coto minero de Hellín ha quedado como testigo actual la denominada "Casa Blanca" rodeada de una serie de hornos y que servía como una de las yeseras de la zona, lo cual le ha otorgado su denominación.

Toda esta época de grandes vaivenes llevados a cabo en la primera etapa de fundación de las minas no hizo más que propiciar el posterior periodo de declive y decadencia que se dio de la mano de un sistema de producción que más que reflejar el crecimiento y avance de la historia, solo mostró el estancamiento en el pasado.

\section{Tendencias tradicionales de la explotación y problemas}

En este periodo fue el cambio de las fuerzas representantes del país el que propició que el próspero futuro que numerosos autores deparaban para la zona se quedara en meras ilusiones, puesto que se dio un giro totalmente radical cuando el sistema de explotación tradicional consiguió desvanecer el progreso de la zona.

Con la llegada de Fernando VII al trono, la propiedad de las minas que hasta ese momento había comenzado un breve periodo totalmente de dominio público, volvió a ser administrada por un ente particular, en donde la delegación de esta propiedad al general Elio supuso una desvinculación aunque no total, de la corona conforme a la explotación. Fue a partir de 1818 cuando este lugar comenzó a ser bastante conocido en todo el mundo, ya que a partir de este momento numerosos autores lo incluyeron en sus obras. Un ejemplo es el caso de Sebastián Miñano, que en la elaboración de su Diccionario geográfico-estadístico de España y Portugal describe la zona de las Minas situada a 4 leguas de distancia de Hellín, en donde caracterizaba esta zona como "las reales fábricas de azufre" debido a la gran importancia que suponían las mismas para la 
corona, aclarando además que "en sus minas hay celestina cristalizada, elinero y papel de montaña y son las más abundantes de España". Por otro lado, tal y como hemos avanzado en el epílogo anterior, ya se comienza a realizar una descripción acerca de la gran fertilidad que estaban comenzando a tener las tierras aledañas de la zona, sobre todo en lo referido a los arrozales que comenzaban a ocupar una posición bastante importante en el paisaje de la zona.

La producción minera que en estos momento tenía una gran relevancia, contaba con una extensión del coto de unos 135 kilómetros cuadrados aproximadamente, con 15 kilómetros de longitud y 9 kilómetros cuadrados de ancho, en donde se contabilizada la explotación de 17 vetas, siendo algunas más abundantes que otras.

A partir de 1854 la administración de las minas pasó íntegramente a depender del Cuerpo de Artillería y comenzaron a darse los mayores problemas en la producción de las mismas. Sumado a la administración desatinada llevada a cabo por el cuerpo, también se produjo una elevada burocratización que acabó elevando los costes y provocando una falta de rentabilidad en la zona que no se había dado anteriormente. Ante estos problemas, se dieron propuestas de privatización por diversos autores debido al cambio en la mentalidad de la sociedad por motivo de los nuevos ideales liberales. Ahora bien, no todo eran problemas devenidos de la obsoleta administración de la zona, sino que también la falta de cualificación de los explotadores y trabajadores de la zona, además de los inconvenientes propios de su idiosincrasia, aumentaron todavía más los inconvenientes.

A este respecto, el informe elaborado por el ingeniero minero Federico Botella y de Hornos titulado descripción geológica-minera de las provincias de Murcia y Albacete, mostraba como la situación de aprovechamiento de las minas estaba totalmente obsoleta.

El principal problema con el que contaba la zona venía dado por el sistema de explotación a cielo abierto, ya que suponía el empleo de 60000 varas $(83,5 \mathrm{~cm}$ de longitud) cúbicas más para mover la tierra, suponiendo así un esfuerzo superior que dificultaba la productividad de la zona. Además de ello, todas las operaciones se realizaban manualmente, por lo que suponía un gasto económico en lo referido a los trabajadores mucho mayor, ya que solamente el proceso de acarreo se realizaba con mulos. Si bien, el sistema de operaciones que se realizaba para obtener el azufre constaba de:

1. El terreno trabajado a cielo abierto era desmontado por los picaceros mediante el golpeo repetido de la superficie de la tierra con un instrumental de barrones de hierro bastante pesado.

2. A partir de este primer proceso, llegaban los llenadores que recogían todos los fragmentos resultantes del golpeo de la tierra en una serie de recipientes de esparto denominados espuertas. 
3. Una vez que todos los fragmentos eran recogidos en estas espuertas, los cargadores depositaban estos fragmentos en grandes recipientes denominados serones que se cargaban sobre los mulos que transportaban la carga.

4. Posteriormente, esta carga llevada por los mulos era conducida por un arriero que trasportaba el material cerca de la zona de los hornos.

5. En esta zona aledaña a los hornos, los trituradores machacaban todos los fragmentos obtenidos en un primer momento a un tamaño base.

6. A continuación, era tarea de los espurgadores seleccionar los fragmentos resultantes que contenían azufre, para finalmente introducirlos en los hornos.

En esta zona, las tipologías de tenencias de los hornos era diversas ya que habían de tres clases: hornos de galera alimentados con atocha, hornos de galera que se fundían con leña y hornos de caldera.

Todo este proceso que se realizaba de la manera más rudimentaria posible, provocaba una gran pérdida del valor del azufre, ya que de un material en el que se obtenía una riqueza mineral inicial de un $70 \%$, finalmente y tras todo el proceso de tratamiento del mismo se reducía a un $19,37 \%$ de riqueza mineral. La utilización de todo este sistema provocaba un gasto mayor además de una gran pérdida de tiempo considerable, por lo que todo ello sumando a las cada vez peores condiciones de salubridad de la zona provocaron que se planteasen nuevas propuestas de perfeccionamiento y abreviación del sistema de producción que no llegaron a producirse en este periodo.

Por otro lado, la competencia a nivel internacional provenía principalmente de Sicilia, ya que mientras el kilo de azufre hellinero se vendía a 128,42 reales, el kilo siciliano se vendía a tan solo 24 reales, entre otras cuestiones por el mejor rendimiento de la zona. Por ello este factor también ayudó a cuestionar si el emplazamiento minero podría aspirar a un futuro o si por otro lado se quedaría estancado en su propio pasado.

Pero si algo terminó de culminar esta época de grandes obstáculos para el desarrollo del coto minero fue la cada vez peor calidad de vida que se fraguaba en esta zona, ya que el asentamiento del pueblo de Las Minas entre dos ríos provocaba que en épocas de verano se dieran grandes plagas de mosquitos que desencadenaban numerosas enfermedades entre la población, provocando que la jornada laboral se redujera exclusivamente a los meses de invierno.

A pesar de todo ello, a nivel nacional la importancia de estas minas era crucial ya que casi todo el azufre que se empleaba durante el siglo XVIII-XIX provenía de las mismas. Se podría decir por lo tanto que el cierre de este segundo periodo finalizó con la exhibición de una gran variedad de muestras de azufre de esta zona en la Exposición de 
Sevilla de 1858, que caracterizaron a la producción minera del alcrebite en Hellín como un elemento clave tanto para la industria como para el Estado 5 .

\section{Una época de gran esplendor}

La entrada en esta nueva etapa estuvo precedida por la publicación de las leyes de minas, sobre todo la que correspondía al 6 de Julio de 1859 en donde se derogaba la pertenencia de la propiedad pública de las minas de Hellín. Este hecho advertía la importancia que cada vez adquiría en mayor medida el conjunto de la industria minera, ya que provocaba que este sector tuviera un marco legislativo en el que apoyarse para su desarrollo.

Se siguieron realizando informes sobre la mala situación en la que las minas se encontraban, en donde "lo complicado de la administración, lo irregular del laboreo y lo atrasado del beneficio" (general Naranjo, 1865) se dejaron olvidados tras la llegada del sexenio democrático a España. Fue en este periodo, en 1870 y tras la enajenación de la corona cuando el dominio del coto de las minas pasó definitivamente a manos privadas, por medio de una subasta pública, bajo el dominio del británico Charles Ros Fell, quien para volver a potenciar la explotación del criadero fundó la "Hellín Sulphur Company Ltd". Sin embargo, el acometido del británico no tuvo éxito, puesto que la compañía quebró y la propiedad volvió a pasar a diversas entidades privadas que no lograron obtener rentabilidad alguna no solo por los defectos que padecían las diversas administraciones de la zona, sino por la defectuosa explotación que se hacía de las mismas, su aislamiento, y sobre todo por el agotamiento de los mejores veneros en donde se disponía de forma natural el mineral.

Dicho proceso de privatización tenía como fin último el mejor aprovechamiento, tanto de las minas como de las viviendas que se habían construido en la zona, para que no se deterioraran por completo.

Debido al fracaso de esta compañía, la posesión de las minas pasó a manos del marqués de Perijaá Manuel Salvador López, quien fundó la "Sociedad minero-industrial del Coto de Hellín", que al contrario que ocurrió con Charles Ros, sí que tuvo un mayor éxito, por lo que ello dio el empuje para el posterior traspaso de esta propiedad a Guillermo O’Shea, oficial del cuerpo de Artillería. Bajo la dirección del mismo, se constituirá la "Sociedad Azufrera del Coto de Hellín”, radicada en Bilbao.

\footnotetext{
${ }^{5}$ Mirar el anexo 1 con el informe económico extraído de datos de la obra de Federico Botella y de Hornos, Descripción geológica-minera de las provincias de Murcia y Albacete. Arte Libro, edición del 4 de Diciembre de 2002. Elaboración propia
} 


\section{Figura 3. Documento oficial de la fundación de la Sociedad Azufrera del Coto de Hellín. Bilbao a 2 de enero de 1902}

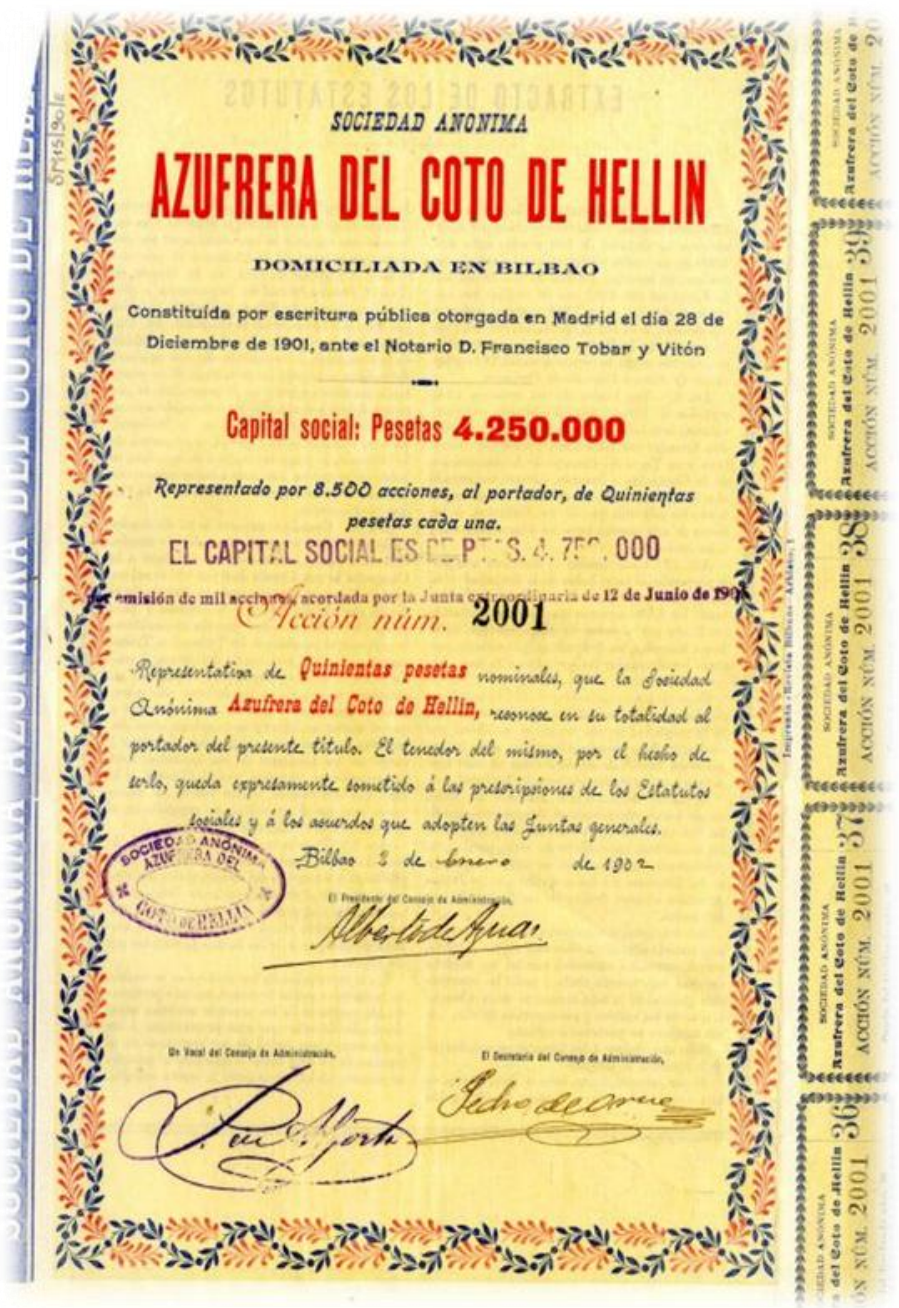

Fuente: Archivo Coto de Hellín.

Si bien cabría destacar que hacia 1901 y debido a la mala situación por la que estaba pasando esta industria minera se produjo el cierre definitivo de la mina, hasta que la llegada del oficial O’Shea propició su recuperación.

A partir de este momento numerosas novedades se implantaron en el coto minero de Hellín. La principal y más importante de todas vino acompañada de la sustitución del sistema de laboreo a cielo abierto, iniciado bajo la tenencia de la propiedad por parte de Manuel Salvador López, que modernizó y mejoró el sistema de explotación sobre todo en un sentido mecánico. El empleo del nuevo sistema de producción consistió principalmente en realizar un método de trabajo que resultase mucho más económico para que no se incrementara el precio del mineral y a la par poder controlar la abundante presencia del agua. Es por ello que la extracción del mineral comenzó a realizarse a partir de dos pozos maestros en los cuales se empleaba un método de jaulas guiadas por 
unas vagonetas de motor eléctrico. Además se construyeron una serie de galerías generales que partían de los pozos maestros y que se encargaban de trasportar el mineral mediante una serie de vagonetas con carriles, por lo que se aligeró mucho el proceso de obtención del mineral. También se mejoró la ventilación en los pozos mediante sistemas de chimeneas y en algunos casos ventiladores de mano, consiguiendo incluso que el desguace de las aguas de la mina se realizase a través de ventiladores centrífugos movidos por motores eléctricos que dieron mayor eficacia a la producción de la industria.

Todo ello vino de la mano de la creación de un ferrocarril de 3,6 kilómetros de longitud que unió los almacenes de las minas con la estación de Minas y finalmente con la línea ferroviaria de Madrid-Cartagena, produciendo así la potenciación de la industria y evitando uno de los principales factores de su declive: el aislamiento secular de la misma. La apertura del servicio se inició a partir de 1904. Aunque los componentes del parque ferroviario eran bastante escasos, ya que solo contó con tres locomotoras, sirvió como gran potencial para sacar adelante una industria que hasta ese momento no había explotado todo su potencial.

\section{Cuadro 2. Datos sobre el equipamiento y locomotoras del tren ferroviario de las minas de azufre en Hellín}

\begin{tabular}{|l|l|l|l|}
\hline \multicolumn{1}{|c|}{ LOCOMOTORA } & TIPO & $\frac{\text { CONSTRUCTOR/NÚMERO }}{\underline{\text { DE FÁBRICA/AÑO }}}$ & \multicolumn{1}{c|}{ CARACTERÍSTICAS } \\
\hline Guillermo & $021-\mathrm{T}$ & DECUAVILLE/291/1900 & $\begin{array}{l}35 \text { caballos de potencia que } \\
\text { permitía remolcar 155 } \\
\text { toneladas a } 9 \mathrm{~km} / \mathrm{h} \text { en } \\
\text { horizontal, con una velocidad } \\
\text { máxima de 13 km/h. }\end{array}$ \\
\hline Hellín & $020-\mathrm{ST}$ & SHARP STEWART/4871/1902 & $\begin{array}{l}8 \text { caballos de fuerza, } \\
\text { transportaba a los mineros }\end{array}$ \\
\hline Arrázola & $020-\mathrm{ST}$ & COUILLET & $\begin{array}{l}9 \text { caballos de potencia y 10 } \\
\mathrm{km} / \mathrm{h} \text { de marcha. }\end{array}$ \\
\hline
\end{tabular}

Fuente: Manolo Serrano a través de los datos proporcionados por la Sociedad Azufrera del Coto de Hellín. Elaboración propia.

Las locomotoras que trabajaban en el lugar arrastraban vagonetas de mineral, vagones medios de puertas laterales para los sacos de azufre y cerrados de bogíes capaces de llevar consigo 5 toneladas, además de una cisterna. Concretando en las características de los vagones, existía un coche de viajeros de Bogies, un vagón de jardinera de dos ejes, 
seis vagones para trasportar cinco toneladas, un vagón cisterna, dos vagones cerrados y dos vagones de bordes bajos.

Posteriormente la creación de una central eléctrica de unos 600 caballos de fuerza en el río mundo junto con la ampliación del campo explotable de la mina lograron crear un ritmo de producción inmejorable en la zona, por lo que se tuvieron dificultades para encontrar buenos mineros y para solucionar este problema se procedió a contratar a población femenina. Se logró por lo tanto extraer alrededor de 480.000 toneladas de mineral de azufre, lo que posicionó a la industria como la primera en el panorama mundial. Las prometedoras y nuevas expectativas del coto minero dieron una situación financiera para la sociedad Azufrera del Coto de Hellín excelente, cotizándose sus acciones en bolsa en un 85 por 100. Además la producción mensual de la zona pasó de las 200 toneladas a las 627 toneladas, por lo que consiguieron una producción total al año de 5.398.531 kilogramos.

Toda esta acción quedó plasmada por el propio oficial de artillería Guillermo O`Shea en la fundación de la empresa Azufrera del Coto que se encargó de demarcar un límite administrativo mucho más conciso para la industria. En estos momentos la extensión del azufre era cada vez mayor, puesto que no solo se convirtió en el instrumento fundamental de la industria química, sino que además sus aplicaciones comenzaron a ser mucho más diversas. Este hecho propició que la sociedad azufrera se quedase con la totalidad del control de la industria, puesto que también se le otorgó la representación comercial del mineral, que anteriormente se había delegado en una serie de comerciales denominados "Sucesores de E.Steinfeldt". Con ello, se monopolizó la atención central de la industria en cuestiones sumamente comerciales, como lo eran la apertura a nuevos mercados o las expectativas de venta de la empresa.

A pesar de los vaivenes de la historia y de los sucesivos inconvenientes que se encontraba la producción minera, se demostró durante esta gran etapa de esplendor que con una eficaz administración del lugar se podía sacar adelante una industria que no solo producía uno de los minerales más preciados de la historia, sino que debido a la gran influencia que ejerció en la zona logró la implantación de una pedanía en sus alrededores que fundamentalmente comenzó con la creación de casas-cueva para los trabajadores, pero que poco a poco y junto con el crecimiento de la industria crearon un pueblo de la nada que logró alcanzar más de 2.000 habitantes, provisto de todo tipo de infraestructuras como podían ser farmacia, cine, médico, tiendas de alimentación, escuelas, bares...

Esta etapa de gran esplendor es el aliciente más característico de la zona, puesto que a pesar de las condiciones de insalubridad tanto de la mina como del pueblo, logró alcanzar un gran renombre en el panorama mundial que hoy vemos olvidado debido al nefasto desenlace que tuvo la historia del lugar. 


\section{Cuadro 3. Producción de la azufrera del coto de Hellín en kilos (1902-1910)}

\begin{tabular}{|l|l|l|l|l|l|l|l|l|l|}
\hline & 1902 & 1903 & 1904 & 1905 & 1906 & 1907 & 1908 & 1909 & 1910 \\
\hline Flor & 61410 & - & - & 1271000 & 1128950 & 937443 & 877508 & 1363160 & 1010584 \\
\hline Terrón 1 & 3505300 & - & - & 3759000 & 4007436 & 4989804 & 2543620 & 3614323 & 4689424 \\
\hline Terrón 3 & 532500 & - & - & 500000 & 1272000 & 1100 & 1000 & 0 & 0 \\
\hline Molido & & - & - & 1240000 & 705088 & 637862 & 821628 & 365448 & 839620 \\
\hline Cañón & & - & - & 31000 & 20738 & 126728 & 40650 & 55600 & 92950 \\
\hline Total & 4099210 & - & - & 680200 & 7134212 & 6728937 & 4736080 & 5398531 & 6920950 \\
\hline
\end{tabular}

Fuente: Daniel Carmona Zurubí. Elaboración propia.

Nota: Los años marcados con un - no ofrecen datos precisos, aunque estiman el total de la producción en más de 7 millones de kilogramos.

\section{El declive y cierre de la producción y explotación de las minas}

Aunque los siglos XIX y XX supusieron la etapa de mayor producción de esta industria del alcrebite, los problemas que ataño habían amenazado el futuro de la mina volvieron a surgir a partir del año 1910 aproximadamente, suponiendo el hundimiento de la industria que ya no pudo "levantar cabeza".

Principalmente los problemas con los que se encontró la empresa Azufrera del coto de Hellín fueron la tradicional escasez mano de obra de trabajadores cualificados que aumentasen los rendimientos de la zona, por lo que se pensó directamente en comprar nueva maquinaria que sustituyera a los mismos, algo que resultó inviable por la falta de capital. Además, los medios de transporte de la mina no podían hacer competencia a los empleados por las azufreras marsellesa, y sobre todo siciliana, que estaba consiguiendo cada vez una mayor cuota de mercado en detrimento de esta mina.

Si bien es cierto que durante la Primera Guerra Mundial que trajo consigo la implicación de Italia en la misma, consiguió eliminar al principal competidor en el mercado del azufre: Sicilia. Con este hecho todavía se auguró a partir de 1917 una cierta esperanza de que la industria pudiera consolidarse en el mercado mundial, aprovechando la debilidad de su principal competidor. Pero a pesar de este rayo de esperanza, el temor de la quiebra de la fábrica provocó que en 1916 se constituyera la Sociedad "Coto minero de Hellín" en Madrid, que junto con el Banco de Cartagena y tras la venta de la mina en otra subasta pública, se encomendaron las tareas de administración de la zona bajo el apelativo de una sociedad anónima.

Fue en 1920 el año clave de un declive totalmente imparable auspiciado principalmente por la entrada en el mercado mundial del azufre estadounidense, que comenzó a fraguarse este mercado durante la contienda de la guerra debido a la escasez de un 
suministro armamentístico desde España y Japón, por lo que creó una industria minera de azufre pero mucho más potente, moderna y de gran aparataje comercial.

Cuando parecía que los problemas de la industria minera en Hellín no podían ir a peor, en los años 1929, 1930, 1932 y 1934 se produjeron grandes huelgas y cierres patronales por los trabajadores de la zona debido a las malas condiciones de producción de las minas como la salud del lugar. Además, en 1934 fue el primer año en el que se tuvo que pagar un seguro obrero obligatorio, por lo que el coste salarial incrementado de la plantilla llevó a la ruina a un negocio que tan solo unos años antes había sido todo un éxito.

Tras la Segunda Guerra Mundial, sobre todo en la época de posguerra, los problemas se fueron incrementando por el desabastecimiento de materias e instrumental para continuar con la producción en la zona, además de por la escasez de personal que tendía a emigrar hacia zonas en donde el salario era más elevado. Pero en la época franquista, debido sobre todo al aislamiento internacional del país, el cierre de la fábrica se prorrogó puesto que todavía esta mina conservaba un papel importante en el comercio nacional, hasta que los inconvenientes y la decadencia de la explotación se hicieron insostenibles.

El punto y final a la producción de la zona vino de la mano de una sequía que se dio en 1945 y que provocó que no funcionase la central eléctrica de la zona, ya que funcionaba por medio de una turbina hidráulica, por lo que los pozos de la mina se anegaron de agua que no se pudo extraer al no haber electricidad en la central.

A partir de ese momento, se siguió dando una decadencia prolongada de la zona hasta el día 20 de octubre de 1960 que fue cuando tuvo lugar el cierre definitivo de la misma. Desde entonces y en un periodo aproximado de 15 años la zona minera de Hellín continuó realizando labores de refino, con azufre importado desde Murcia, La Coruña y Francia, ya que la gran explotación que se dio de la misma acabó casi con la totalidad del mineral.

A pesar del declive de la zona, la propiedad del lugar ha seguido pasando por numerosas manos tras el año 2002 en el que la Sociedad Coto Minero abandonó las labores de administración, derogando la propiedad de la zona a Tomás Sánchez Pérez, quien recientemente volvió a vender la propiedad a otro colectivo privado. 
El paisaje actual que nos ofrece este emplazamiento es prácticamente el de un espacio abandonado y desolado con la existencia de casas cueva totalmente en ruinas, oscuras e insalubres en donde el proceso de silicosis ${ }^{6}$ contribuyó al abandono definitivo de dichas cuevas, junto con la existencia de pozos que se han convertido en grandes vertederos que contaminan las aguas subterráneas, que terminan de conformar un panorama totalmente desolador.

Fue tal el potencial que este espacio adquirió de la nada, que a pesar del abandono de la industria el pueblo de Las Minas se ha mantenido a lo largo del tiempo con una tendencia a perder población, pero quedando como el principal testigo de una gran época de esplendor minera que ha dejado grandes vestigios de lo que en un pasado fue trascendental para la historia.

\section{CONSECUENCIAS DE LOS PROCESOS EXPANSIVOS DE URBANIZACIÓN EN DETRIMENTO DEL ESPACIO RURAL DE LAS MINAS}

En este apartado del trabajo se analiza un proceso de urbanismo en el medio rural que ha suscitado una gran polémica y que a la par ha tenido influencia en el emplazamiento de Las Minas debido a la proximidad a la que se encuentra (unos 5-7 km aproximadamente), y se conoce bajo en nombre de la construcción urbanística Las Higuericas.

Este ejemplo no es más que otro de los casos en que el mundo urbano se ha intentado sobreponer al rural y que más tardíamente relacionaremos con una gran problemática que se ha generado recientemente en el poblado minero de Las Minas ya que se encuentra íntimamente relacionada con las ansias urbanísticas que tantas veces han ganado terreno al espacio rural.

Referido a la urbanización Las Higuericas que se sitúa entre las pedanías Agramón y Las Minas pertenecientes a Hellín, que apenas se encuentran separadas por 14 km, si analizamos profundamente su historia desde el momento de su creación, vemos como el proyecto se inició en el año 2003 proclamándose desde entonces como uno de los grandes pelotazos urbanísticos que iba a darse en España. Fue un proyecto iniciado por la empresa Cleyton GES S.L que constaba desde sus inicios con la construcción de más de 600 casas adosadas en donde algunas de estas construcciones también se avalaron por la CAM.

Desde sus comienzos el megacomplejo urbanístico ya contó con un inconveniente principal que en muchos casos se ha pasado por alto, ya que el emplazamiento se

\footnotetext{
${ }^{6}$ Silicosis. Proceso de contaminación del aparato respiratorio de las personas producido por el polvo de minerales, en este caso del azufre. Este proceso contaminador se extendió gravemente por la falta de control de las condiciones sanitarias, terminando por invadir este conjunto de casas-cueva que fueron totalmente abandonadas.
} 
encuentra en el espacio protegido de las Sierras y Cañones del Segura y el río Mundo, ocupando un espacio de más de 60 hectáreas, declarado LIC (lugar de interés común) y ZEPA y por lo tanto perteneciente a la Red Natura 2000. Este simple hecho tendría que haber representado desde un primer momento una negativa rotunda a la construcción debido al carácter del paraje, pero la Delegación de Medio Ambiente de Albacete declaró la no evaluación de impacto ambiental de la zona por lo que se procedió a la construcción sin más. En este primer punto de partida es donde cabe cuestionar hasta qué punto la expansión urbanizadora de las zonas rurales pueden afectar a un territorio, puesto que la construcción de dicho lugar rompió por completo con la dinámica natural de la zona y sus alrededores provocando una gran pérdida de valor paisajístico de la zona.

Si los comienzos de este proyecto ya contaron con algunas trabas, mucho peor fue el desarrollo del mismo ya que en la actualidad y tras más de 9 años lo que nos encontramos al pasar por la zona es una gran cantidad de casas casi sin construir que nos muestran la imagen de un paisaje totalmente contaminado por "casas esqueleto".

Los británicos eran el principal grupo atraído por esta nueva urbanización que se decidió edificar para este sector concreto de población que hacia el año 2008-2009 comenzó a invertir su dinero para la compra de sus casas. A partir de este momento fue cuando se desencadenó todo el pleito referido a este espacio puesto que para ese año solamente se había construido 36 de las 671 viviendas que se habían planificado, sin ni siquiera la célula de habitabilidad. Desde entonces y tras la decisión por parte de la empresa de abandonar la construcción por falta de rentabilidad y de beneficios se ha desencadenado una trama judicial en la que los ecologistas y el grupo de población británica son los principales denunciantes de la situación. 


\section{Figura 4. Imagen panorámica de la urbanización Las Higuericas situada entre el río Mundo y el pantano de Camarillas}

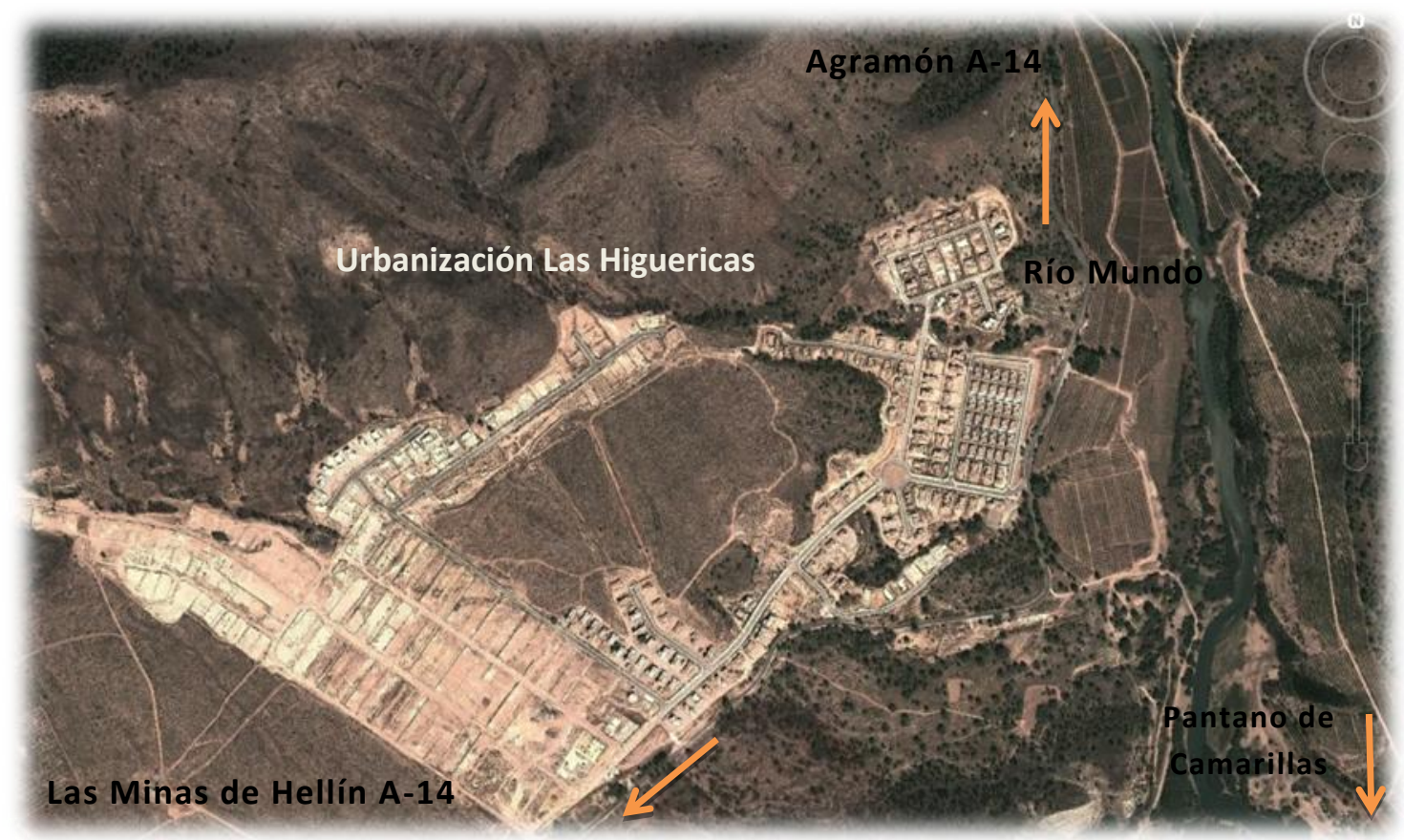

Fuente: Imagen de Google Earth 2013. Elaboración propia.

Si bien es cierto que este plan de urbanización recibió en 2006 uno de los premios a las cinco mejores promociones inmobiliarias de toda España y a la mejor de Albacete, pero el próspero futuro del proyecto se vio totalmente truncado desde el momento en que se encubrió la ilegalidad del mismo. Al igual que la constructora recibió un premio por lo brillante de su trabajo, por otro lado los británicos afectados también deberían de recibir otro como gran ejemplo del colector que lucha por sus intereses demostrando que una solución justa se puede obtener. Así y tras la fundación del FINCA PARCS ACTION GROUP que es el nombre bajo el que este colectivo formó una asociación, se han llevado a cabo numerosas protestas y denuncias para conseguir que este delito no quedara impune. Un gran ejemplo de ello es el boicot contra la presencia de España en la feria inmobiliaria que se realizó en Reino Unido y que este grupo denunció poniendo su caso como ejemplo a los fraudes que se estaban realizando.

$\mathrm{Y}$ es que cuando se trata de negocios vemos cómo se pueden superar todo tipo de barreras ya que desde tiempos históricos Hellín ha tenido una gran disputa con Murcia por estas tierras ya que se encuentran en la frontera entre ambas provincias, por lo que siempre han tenido una gran rivalidad, pero a la hora de firmar contratos y convenios urbanísticos no tuvo ningún problema de hacerlos con empresas murcianas.

En la actualidad y tras varios juicios realizados la sentencia ha sido clara, ya que tanto la empresa como la entidad financiera tendrán que pagar en total 1,5 millones de euros de indemnización a los 55 británicos que invirtieron dinero en estas casas que jamás les 
han sido entregadas. Esta sentencia dictada por el juzgado de Primera instancia de Hellín también le ha imputado a la CAM "mala praxis bancaria" ya que la entidad financiera tendría que haber destinado el dinero ingresado por los británicos (15292€ cada británico) a recursos para las construcciones que sin embargo jamás se dieron.

Tal ha sido la ilegalidad en esta urbanización que incluso la empresa Cleyton GES y la CAM se encuentran en disparidad de opiniones y en graves conflictos puesto que después de que en esta zona se saqueara todo el material de construcción, la CAM se ha otorgado la custodia de los bienes de la zona para evitar los expolios, impidiendo además el paso a estas instalaciones a trabajadores de la empresa, ya que en numerosas ocasiones se ha querido volver a relanzar el proyecto sin ningún éxito.

Tanto ecologistas como el colectivo británico en una incesante lucha han logrado por un lado parar la construcción de la urbanización y por el otro obtener una sentencia legal acorde con las pérdidas que han sufrido por invertir en la zona. Ahora bien, a pesar de ello el daño que se ha hecho en este emplazamiento es irreversible puesto que se han destruido cerca de 60 hectáreas de un espacio protegido de gran valor paisajístico y todo ello por los intereses de obtener beneficios económicos a costa de un espacio débil: el mundo rural.

Si extrapolamos este ejemplo lo podemos aplicar perfectamente a un suceso que desde hace varios meses ocurrió en la zona concreta del poblado de Las Minas de Hellín. Justo en la entrada del pueblo y en lo referido a las ultimas edificaciones que se hicieron con la construcción de tres grandes bloques de vivienda en altura de 4 plantas cada uno, en la actualidad uno de ellos, el bloque de en medio, se encuentra en ruinas y se va a proceder a la demolición del mismo. Ahora bien, el principal problema es que no es el bloque entero el que se encuentra en ruinas sino solo una parte, por lo que en la parte que en buen estado todavía hay gente viviendo y sin embargo la demolición iba a afectar a la totalidad del edificio.

Todo ello generó una gran sorpresa en los habitantes de la zona puesto que la parte en ruinas del bloque de pisos lleva en este estado desde el año 2009 aproximadamente, y tras tres años en este estado es ahora cuando se iba a proceder a su demolición, afectando a la totalidad del bloque. Por otro lado, si consideramos también la condición de que son los vecinos, en su totalidad población envejecida, los que tenían que hacerse cargo de los gastos de la demolición abonando cada uno alrededor de 5000 euros vemos como la polémica todavía era aún mayor. Al ser una población envejecida la mayoría de ellos no contaban con los recursos suficientes para poder acarrear con estos gastos.

Fueron declaraciones de la gente del lugar las que nos llevan a pensar, ¿por qué han esperado casi 3 años desde que se declaró el edificio en ruinas a demolerlo?, o ¿por qué encima de que nos quitan la casa tenemos que pagar por ello? En este caso y no como ocurrió en la urbanización de Las Higuericas, como el colectivo de población no era suficiente, puesto que apenas eran unas 10 familias las afectadas, las acciones 
emprendidas para paralizar estas demoliciones en un principio no fueron suficientes ya que según ellos "no veíamos llegar este momento".

Es en este punto donde podemos plantearnos hasta qué límites la población rural está desprotegida en cuanto al conocimiento de sus derechos y oportunidades, puesto que este lugar es el claro ejemplo de la resignación de una localidad que piensa que no tiene posibilidades de salvaguardad los bienes que se generaron en el lugar y que les pertenecen.

Según la sentencia que se emitió en el mes de Abril, sería a finales de Mayo o principios de Junio cuando irremediablemente se produjera la demolición del bloque de edificios, llevándose consigo una gran cantidad de historias vividas por parte de los propietarios que desde que su nacimiento habían contribuido al desarrollo del lugar y que hoy en día veían totalmente mermado.

"Por el bien de los habitantes de la zona" era el precepto con el que se partía el derribo del edificio debido al mal estado del mismo y al peligro que ocasiona para los habitantes del lugar, sin embargo el principal inconveniente es que afectaba a personas que residían en el sector en buen estado del edificio, pero como solamente era una persona la que tenía su residencia en esta parte, no servía de pretexto para evitar la demolición. Todo ello ha llevó a pensar en posibles intereses de reurbanizar en el lugar ya que había mucha gente que no veía clara la sentencia emitida.

Finalmente, con la ayuda de terceras personas a esta población tan envejecida, se logró apelar esta sentencia inicial para que solamente se demoliera la parte derruida del bloque de edificios, y así la parte intacta de dicho bloque no se tocara. Aun así, todos los vecinos que residían en estos edificios se han tenido que hacer cargo de los gastos de la demolición, aunque reducidos conforme a la cantidad inicial, pero siendo bastante superiores a lo que ellos se podían permitir.

Habiendo resultado un poco más favorable la sentencia final para estos vecinos, todavía quedan algunas dudas de que es lo que verdaderamente ha pasado aquí y porqué se ha esperado tanto tiempo a demoler un edificio que desde hace años estaba ya en ruinas.

Este no es más que otro de los ejemplos de que el mundo rural tiene muy poca protección en algunos sectores y que solamente indagando dentro del mismo se puede llegar a conocer tanto el gran interés cultural que suscitan por sus modos de vida como la complejidad del desarrollo en su día a día que entraña el luchar por preservar espacios cada vez en mayor decadencia y abandono.

Con ello solo queda plantear si, ¿es esta la primera iniciativa de la reconversión del lugar?, ¿el desamparo de la población afectada será el principio del abandono del mismo?, o ¿es solamente un caso de protección de la población debido a las malas condiciones de la vivienda? La mayoría de estas preguntas no tienen todavía una 
respuesta posible ya que solamente el tiempo dirá si una vez más otro espacio rural de un gran valor tanto histórico como cultural desaparecerá o no.

\section{POSIBLES SOLUCIONES A UN ESPACIO OLOVIDADO; ¿HACIA LA REVALORIZACIÓN O LA RECONVERSIÓN?}

En este último apartado del artículo se han abarcado algunas de las posibles soluciones para rescatar del abandono la pedanía de Las Minas de Hellín trazando a la par dos posibles vías mediante las cuales se pueden llevar a cabo estas actuaciones.

Antes de comenzar a indagar en el fondo de estas cuestiones, cabría mencionar que en la actualidad ya se han realizado una serie de Planes de Actuación en la zona para poder acondicionarla y así mostrar a los visitantes su historia a partir de los restos que todavía se conservan de la explotación al igual que las condiciones de vida en las que se desarrollaba el día a día de los mineros que trabajaban en dicha industria. Además mediante estos planes también se ha pretendido materializar una recuperación medioambiental y mejora en las condiciones de vida del emplazamiento que sin embargo no han logrado obtener los resultados que desde un principio se pretendían.

Tal y como se ve reflejado en el título de este apartado del trabajo, la cuestión principal es plantarse cuál sería la actuación más adecuada en esta zona, ¿una revalorización o una reconversión? Referido a estos dos conceptos, cabe mencionar que se habla de revalorización desde el sentido de aprovechar todo lo que nos ofrece el espacio y las infraestructuras que ya se han desarrollado para con una mejora y adecuación de las mismas poder obtener un mayor potencial de este espacio rural que nos ayude a prestar soluciones de futuro a la zona. Y por el contrario, cuando se habla de reconversión se alude a un cambio total de la zona, es decir, aprovechando lo más mínimo posible lo que ya nos ofrece el lugar, cambiado totalmente su dinámica hacia un sector que obtenga mayores beneficios en Las Minas.

Partir de esta primera premisa muchas veces es complicado puesto que se podría considerar que ambas actuaciones son adecuadas, ya que con la primera se respeta lo que ya tenemos en el espacio, y con la segunda logramos obtener un mayor beneficio y una mayor rentabilidad en el lugar.

La solución a este primer problema que se puede plantear está en el hecho de realizar el denominado trabajo de campo en el lugar, es decir, radicaría en realizar investigaciones in situ, entrevistar a las gentes del pueblo, recorrer el espacio viendo cuales son los principales elementos que sobresalen en el mismo, etc... Todo ello contribuye a obtener una mayor visión sobre cuál es la línea de actuación más adecuada que necesita dicho emplazamiento, que sin conocer de antemano resulta difícil poder plantear. Una vez que se ha realizado este primer paso, se muestran las grandes necesidades que en cuanto a infraestructuras, como el simple abastecimiento de agua, son necesarias en este lugar, 
puesto que a pesar de encontrarse en el mismo río Segura, los medios para abastecerse de agua son bastante deficitarios y es por ello que desde el ministerio en la actualidad se ha llevado a cabo un plan para la mejora de estos sistemas, que bien se puede considerar como una actuación encaminada a la revalorización del lugar, hecho que es bastante positivo.

Por otra parte, el paso del río Segura por la zona además de ser un hecho beneficiario por el gran valor cultural y paisajístico que le otorga también ha resultado una traba al desarrollo de la calidad de vida del lugar, puesto que proporciona una gran carga de humedad y en determinadas épocas del año como en el verano las plagas de mosquitos que se dan son un condicionante que provoca una gran insalubridad, que sin embargo tal y como afirman sus vecinos "ya estamos acostumbrados". A este respecto, también cabe añadir que debido a las prácticas agrícolas que se realizan en el paso del río el mismo se encuentra bastante contaminado, y además en numerosos lugares de la pedanía no está controlado por lo que en cualquier momento puede sufrir un peligro de desbordamiento.

En este punto sería interesante plantear, ¿por qué no utilizar en beneficio propio un recurso que de manera gratuita nos proporciona la naturaleza? Es en este momento cuando si otorgamos una revalorización del lugar podríamos encontrar una de las mejores soluciones para rescatar del olvido este espacio. Ya que se tiene una ventaja en cuanto al lugar estratégico en donde está localizada la pedanía, si se llevaran a cabo actuaciones para sanear la ribera del río ya que es la parte más colindante con el pueblo, y si se controla el desbordamiento que en algunos tramos sufre el río, las condiciones de vida de la población mejorarían.

Tras todos los análisis tanto físicos como demográficos que se han realizado en Las Minas y a partir de las premisas que acabamos de mencionar, sería conveniente partir desde el punto de vista de una revalorización del lugar puesto que el arraigo territorial que la población tiene en la zona y el gran valor cultural e histórico que posee hacen que la revalorización sea la mejor salida a considerar para este espacio, puesto que si se reconvirtiera perdería gran parte del valor cultural y social que todos sus vecinos y la propia historia se ha encargado de darle a través del paso del tiempo.

Así pues se ha podido analizar como la propia idiosincrasia del lugar es la que lleva a pensar que si a pesar de todos los inconvenientes como es el entorno físico del espacio, se ha podido desarrollar este lugar y logró posicionarse como una de las zonas más importantes en el historia de España, si se cambiara su dinámica que de por sí sola ha generado tanta riqueza, probablemente acabaría por destruir los rasgos que siempre lo han definido y caracterizado. 


\section{Cuadro 4. Esquema de las posibles líneas de actuación sobre Las Minas de Hellín}

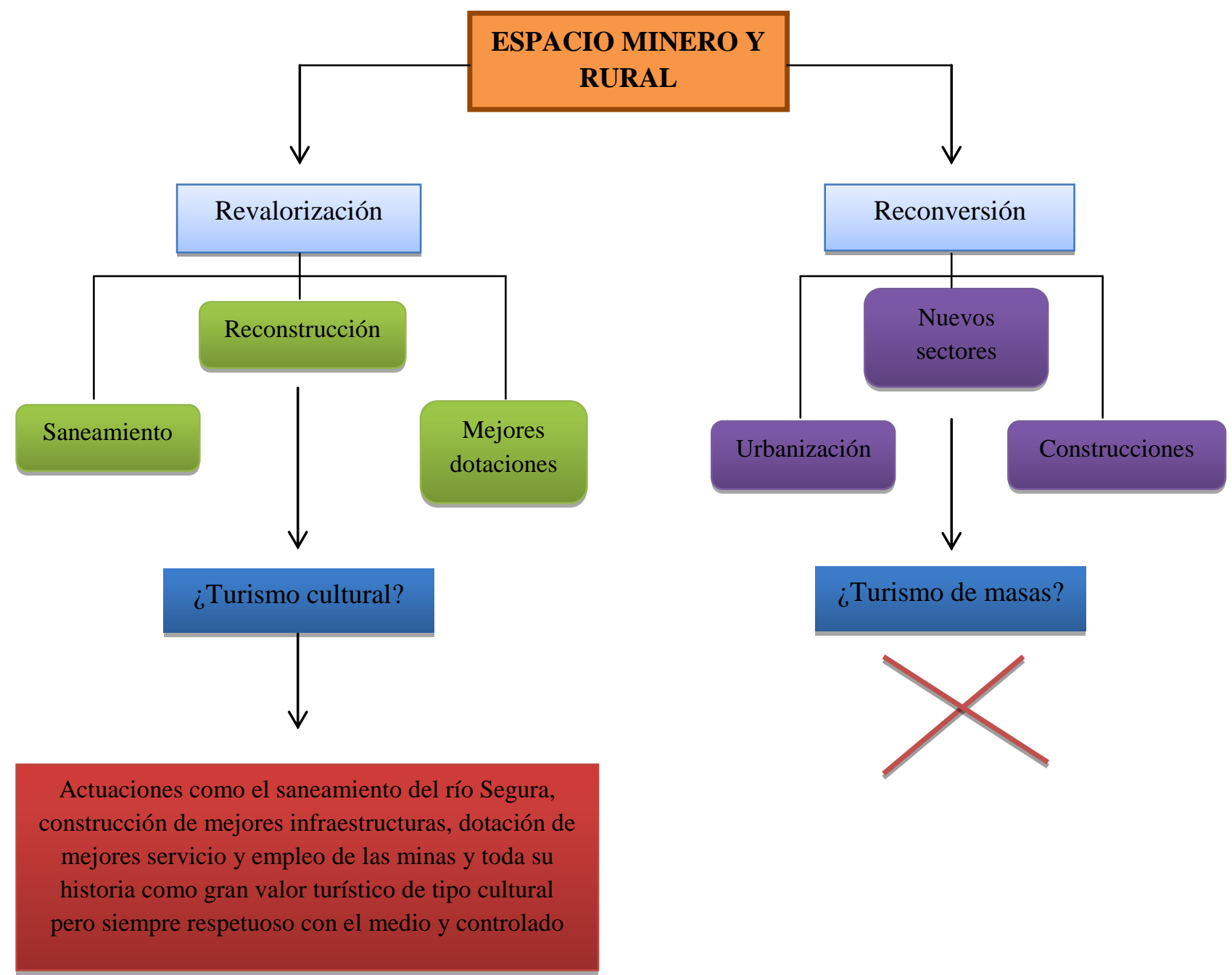

Fuente: Elaboración propia a partir de los datos obtenidos en el trabajo de campo en Las Minas de Hellín. Marzo 2013.

Mediante obras de adecuación y saneamiento de los pozos de las minas, de las casascueva, de las zonas urbanizadas en el lugar, de los medios de transporte, de las instalaciones, etc., se puede llevar a cabo un proceso de revalorización del pueblo que para nada afecte negativamente a las actividades que durante tantos años han mantenido el poblado y que han logrado crear una sociedad, y que además ayuden a destacar y a rememorar esa historia que ha quedado enterrada dentro de un espacio que no ha sido valorado.

Cabría destacar también que no solo hay un gran valor cultural en Las Minas, sino que todos los pueblos colindantes y las zonas adyacentes de esta pedanía debido a que pertenecen al sistema protegido de Sierras y Cañones del Segura son objeto de gran valor, como por ejemplo los Pantanos de Camarillas y del Cenajo, ambos muy cercanos al espacio analizado, por lo que también se podrían aprovechar para incrementar el 
atractivo turístico del lugar, ya que ambos tiene un gran renombre, al igual que la zona de Calasparra que tan solo se sitúa a $20 \mathrm{~km}$ de Las Minas y que tiene un gran valor turístico debido a sus fiestas y a los espacios tanto religiosos como históricos que se pueden visitar en el lugar. También las numerosas rutas de senderismo que se realizan por los alrededores de la zona terminan de completar un gran complejo atractivo turístico que se podría desarrollar en estas tierras. Y es que no solo se puede partir de esa base, ya que cosas tan pequeñas como es el instrumental de las campanas de la iglesia de Las Minas las cuales se mueven a partir de uno de los mecanismos de reloj manuales más antiguos que existen, nos muestran que el valor que un pequeño espacio rural alcanza muchas veces es mayor a sus dimensiones.

A este respecto después de todo lo que analizado cabría cuestionar que en numerosas ocasiones el medio rural es un espacio infravalorado a pesar de los grandes atractivos que encierra, simplemente por la connotación despectiva que ha adquirido con el paso del tiempo. Así pues en este ejemplo concreto se ve claramente como un espacio rural tras la pérdida de importancia en el territorio nacional como industria ha sido totalmente infravalorado, dejando en duda que, ¿ha sido simplemente por el hecho de ser un espacio rural por lo que ha perdido importancia a pesar del gran valor estratégico que siempre ha tenido y que todavía conserva en la actualidad?, porque si bien es cierto que en el pasado fue un lugar estratégico desde el punto de vista bélico e industrial para la fabricación armamentística, en la actualidad lo sigue siendo por su posición entre dos ríos, el Mundo y el Segura que lo han dotado de una singularidad única.

En numerosas ocasiones hasta que no ocurre algún hecho muy negativo no se emprenden medidas para paliar los defectos que se dan en algún espacio, al igual que ocurrió el pasado año en las Sierras del Segura, ya que tras un grave incendio numerosas pedanías, incluida la de las Minas tuvieron que ser desalojadas, dejando un paisaje totalmente devastador ya que gran parte de esta zona protegida se encuentra en la actualidad totalmente abrasada, y es justo ahora cuando han comenzado a darse labores de recogida de rastrojos en estas sierras, que agravaron mucho más el incendio puesto que en su mayoría se encuentran sin ningún cuidado ambiental ni sanitario.

Como conclusión a todo lo expuesto solo queda mencionar y resaltar que el espacio rural es un medio bastante desprotegido y desolado pero que en su gran complejidad de paisajes encierra espacios verdaderamente bellos y dignos de admirar a la par que vulnerables, que tan solo con un adecuado cuidado y protección podrían llegar a obtener un valor histórico y cultural incalculable. Así pues, ¿no se podrían plantear mayores consideraciones y recursos hacia un espacio rural que muchas veces nos enseña que alterar la propia dinámica del medio solo nos trae consecuencias negativas? De este modo damos por finalizado el análisis de este emplazamiento que nos ha mostrado como la conservación de un medio rural es posible a pesar de las complejidades que se presenten contra el mismo. 


\section{CONCLUSIONES}

Se puede decir que el valor tanto histórico como cultural que presenta este emplazamiento es bastante importante puesto que en el trascurso y desarrollo de la minería de azufre nacional ha obtenido mucho valor tras posicionarse como la principal mina productora a nivel nacional, pero sin embargo, dicha importancia ha quedado totalmente difuminada en la actualidad ya que es un espacio castigado por las huellas del olvido y el abandono.

Además, no hay mejor manera de conocer la idiosincrasia de un espacio que interactuando con las gentes que lo habitan, puesto que ellos son los principales testigos directos de como el lugar en el que viven ha ido evolucionando con el paso del tiempo, y no hay mejor historia que la que construye un mismo. Es por ello, que las principales conclusiones que se extraen del trabajo provienen de testimonios reales, de sucesos vividos y relatados por las propias personas de la pedanía.

De todo ello, se puede apreciar como el cambio de las viviendas en casas-cueva, que incluso tardíamente se seguían manteniendo como modo de vida en el poblado, a la construcción de bloques de edificios y viviendas de una sola planta, es a la par el cambio a partir del cual la decadencia del lugar se pronunció todavía más. Tras el cierre de la mina, esta pedanía reconvirtió su actividad al sector agrario, sobre todo en lo relacionado con los arrozales, aprovechando al igual que se hizo en la mina el paso del río Segura, por lo que años después del cierre definitivo de la industria, todavía se seguía prosperando y manteniendo gracias a este sector. Pero a partir de la modernización del mismo que podemos considerar que se dio con la construcción de las nuevas viviendas que sustituyeron a las casas-cueva fue cuando comenzaron a darse grandes problemas de deterioro y abandono cada vez más pronunciados.

Quizás si se hubiera mantenido la dinámica natural del lugar sin anticipar la modernización del mismo hubiera prosperado mucho más y en la actualidad no sería una pedanía casi en ruinas, o quizá es que dicho lugar estaba destinado al olvido como algunas personas de las pocas que lo habitan consideran. Pero el hecho fundamental es que no se ha sabido apreciar el valor del mismo desde tiempos históricos, y quizá este sí que puede haber sido el hecho desencadenante que lo ha convertido en un espacio cada vez más rural, no habiéndolo iniciado hacia un camino leve, aunque valioso a la modernización, que lo ha llevado a un profundo olvido.

Las personas que emigraron del lugar por motivos de prosperidad todavía hoy deciden ir a pasar sus vacaciones a este pueblo, y es alomejor en este aspecto donde se puede encontrar una solución a su pérdida definitiva. Si tras abandonar Las Minas la población todavía decide volver en ciertos momentos de su vida es porque el lugar aún guarda un encanto único que ha hecho que a pesar de que lleve años sumergido en una tendencia de pérdida de población y en un deterioro de sus espacios mantenga zonas y bienes que recuerdan a su gran momento de prosperidad y desarrollo, potenciando un arraigo 
territorial por parte de las personas que han crecido en esta pedanía muy difícil de olvidar.

A pesar de todo lo que haya podido pasar en este lugar y los vaivenes que la historia ha dado al mismo, es cierto que recientemente la poca población que reside en el se esfuerza por preservar símbolos tan importantes como lo son sus fiestas, que cada año en el mes de Agosto se celebran atrayendo a familiares de los ancianos que todavía residen en la zona y a las personas que nacieron en la misma. No obstante este acontecimiento siempre ha estado rodeado de controversias puesto que la cercanía que las Minas tienen con Murcia ha provocado que se sientan más murcianos, renegando en ocasiones de las costumbres de Hellín que es el municipio al que pertenecen, y que vemos ejemplificada en sus fiestas ya que las celebran a la par que Murcia.

Solo queda mencionar a todo este respecto que son muy pocos los trabajos que en la actualidad se ha hecho sobre la zona, lo que dificulta mucho su estudio ya que no hay muchas publicaciones concretas sobre el lugar, probablemente por la fecha de cierre en 1960 de la industria que supuso el olvido de este espacio ya que era su principal motor sustentador. Pero a pesar de que se cerró la industria, el hecho más importante es que este poblado que se levantó para albergar a los trabajadores de la mina no se hundió con la misma si no que se ha mantenido hasta nuestros días, por lo que tendría que ser objeto de diversas investigaciones ya que nos sirve para analizar como un espacio reconvertido en el que su principal motor sustentador se hundió, ha sabido salir a flote a pesar de las condiciones negativas y de los grandes inconvenientes que se le han presentado para ello.

Por lo tanto, sería muy interesante plantear y analizar la gran complejidad que mantienen Las Minas y que ha provocado tanto que se haya abandonado por la dificultad que supone la vida en el mismo, pero a la par ha dejado impregnado sobre sus habitantes tanto actuales como pasados un sentimiento de afecto y cariño por el lugar y su gran conjunto de bienes como los ríos, las zonas de minas abandonadas y las casas cueva, que hacen inevitable la vuelta en determinados momentos del año al lugar.

\section{BIBLIOGRAFÍA}

ALONSO, Pilar y GIL, Alberto. Pueblos abandonados. El pasado deja huellas. Revista Añil, 2000, no 21, p. 53-56.

BELLÓN LÓPEZ, Sebastián. Arqueología Industrial en Castilla - La Mancha: las minas de azufre de Hellín. Revista Añil, 2003. no 25, p. 63-65.

BOTELLA y DE HORNOS, Federico. Descripción geológica-minera de las provincias de Murcia y Albacete. Arte Libro, edición del 4 de Diciembre de 2002. Imprenta del Colegio Nacional de Sordomudos y Ciegos MDCCCLXVIII. p. 41, 56-58 y162-166. 
CARMONA GONZÁLEZ, Alfonso. El noroeste murciano en época árabe. Revista Miscelánea Medieval Murcia, 1998, nº 21-22, p. 59-70.

CARMONA ZURUBI, Daniel. Las Minas de Hellín (Albacete). Albacete: Instituto de Estudios albacetenses "Don Juan Manuel" de la Diputación de Albacete, 2007, no 176. $240 \mathrm{p}$.

DE LOS COBOS ARTEAGA, Francisco. Los caminos del Azufre. Transporte y negocios de os O’Shea en Hellín. Revista Studia Academia, 2000-2001, no 11. p. 99131.

FERIXA y RABASÓ, Eusebio. Legislación de Minas. Madrid: Publicaciones de Eusebio Ferixa y Rabasó, 1887. p. 46.

Gaceta Minera y Comercial-Minas de Azufre del coto menor de Hellín en Minas (Albacete). Sociedad Anónima “Azufrera del coto de Hellín”. Revista Gaceta Minera y Comercial. Cartagena, 1904, nº 1109.

Gaceta Minera y Comercial. Sindicato Minero de la Provincia de Murcia. Revista Gaceta Minera y Comercial. Cartagena, 1901, nº 963.

GARCÍA CEBALlOS, José (Dir.) y CAMPOS, Ricardo (Adm.). Revista decenal, hacienda - seguros - banca - bolsa - industria - comercio - agricultura - actualidades. Revista Ilustración Financiera, 1910. nº 32, p. 172-173.

GÓMEZ MARTÍNEZ, J. A. y COVES NAVARRO, J. V. Ferrocarriles mineros en Albacete. Revista Carril, 1991, n 34. p. 14-29.

MIÑAO y BEDOYA, Sebastián. Diccionario geográfico-estadístico de España y Portugal. Madrid: Imprenta Pietra-Peralta, 1826-1828. Tomo IV. 440 p.

ORTIZ HERAS, Manuel; RUIZ GONZÁLEZ, David y SÁNCHEZ SÁNCHEZ, Isidro. Movimientos Sociales y Estado en la España Contemporánea. Servicio de Publicaciones de la Universidad de Castilla-La Mancha, 2001. 605 p.

RODRÍGUEZ DE LA TORRE, Fernando. Dichos, coplas y versos tópicos de la mancha y de la provincia de Albacete. Instituto de Estudios Albacetenses "Don Juan Manuel". Albacete 2000. Serie 1, Estudios, no 122. 244 p.

RANKIN DÍAZ, V. Electricidad, Comercio, Obras Públicas, Metalurgia, Navegación, Agricultura, Aduanas, Minas y Tranvía. Revista Ilustrada de Banca, Ferrocarriles, Industria y Seguros. Madrid, 1987. 510 p.

VILAR, Juan Butista y EGEA BRUNO, Pedro María. Aproximación a la minería albacetense contemporánea (1840-1930). Revista Alb-Aasit, 1985. n 19, p. 33-67. 


\section{RECURSOS ELECTRÓNICOS}

Anónimo. Diseño de las minas de azufre del término de Hellín, 838 (Albacete). MPD, 47, 030. Catálogo Colectivo de la Red de Bibliotecas de los archivos estatales. Ministerio de Educación, Cultura y Deporte. Enero de 1591. <http://www.mcu.es/ccbae/es/consulta/ >. [04 de Abril de 2013].

DE LOS COBOS ARTEAGA, Francisco. Ferrocarril de las Minas de Azufre de Hellín a la estación de Las Minas. Federación Castellano-Manchega de Amigos del Ferrocarril. Año 2001. 〈www.fcmaf.es $>$. [01 de Abril de 2013].

Diario La Verdad. Hellín. La Urbanización de las Higuericas, denunciada ante anticorrupción. Miércoles 11 de Octubre de 2006. 〈www.laverdad.es>. [28 de Marzo de 2013].

El Digital Actualidad. Las Higuericas: condenadas a devolver 1,5 millones. 09 de Junio de 2012. 〈www.eldigitalcastillalamancha.es>. [05 de Abril de 2013].

Instituto Nacional de Estadística (INE). Cifras Oficiales del Nomenclátor de 2012. 〈www.ine.es $>$. [5 de Abril de 2013].

J.D.A. El fiasco de las Higuericas llega al gobierno británico. Diario La Verdad. 02 de Noviembre de 2011. <www.laverdad.com>. [02 de Abril de 2013].

PERIS TORNER, Juan. Ferrocarriles de España. Ferrocarril del Coto Azufrero de Hellín. 04 de Mayo de 2012. <http://www.spanishrailway.com>. [10 de Abril de 2013].

SÁNCHEZ, Emilio. Intento frustrado de retomar las obras en las Higuericas. Diario La Verdad. 07 de Septiembre de 2011. 〈www.laverdad.com>. [02 de Abril de 2013].

SERRANO, Manolo. Manolo Serrano. Últimos testimonios del vapor en España, ferrocarriles mineros, industriales y militares. Sociedad Azufrera del Coto de Hellín. Año 2013. <http://www.manuserran.com>. [15 de Abril de 2013].

VICENTE, Mariano. Río Mundo, primera jornada Leitor - Las Minas. BICIMUR, Amigos de la Bicicleta de Murcia. Murcia. Año 2012. < http://www.bicimur.murciaregion.com/murciaenbicicleta/index.htm $>$. [06 de Abril de 2013]. 


\section{ANEXO 1. COSTES DE PRODUCCIÓN APROXIMADOS DE LAS MINAS DE AZUFRE.}

\section{Valencia, 3 de Septiembre de 1857. Federico Botella y de Hornos}

Gasto relacionado con las varas $(83,5 \mathrm{~cm}$ de longitud $)$

Se emplean los cálculos con dos sistemas: el primero considerando por separado las capas estériles del suelo, el segundo considerando conjuntamente dichas capas.

- 2000 varas cuadradas $\times 2,06=4100$ varas cúbicas $\times 75$ arrobas $=304500$

- 2000 varas cuadradas $\times 0,30=500$ varas cúbicas $\times 75$ arrobas $=45000$

- $\quad$ Total $=349500$ arrobas

Cálculos relacionados con el gasto de los jornaleros

- 90 picaceros a 6 reales $=540$

- 7 tiendas de ocho hombres cada una a 6 reales por operario $=336$

- 90 pares de acémilas con 90 arrieros, a 12 reales el par incluyendo el jornal del arriero $=1080$

- Gasto diario $=1956$ reales

- $\quad$ Por los 140 días de trabajo $=273840$

- $\quad$ Recomposición de herramientas $=10000$

- Compra de astiles, espuertas, cargas de romero, carros, etc $\ldots=8000$

- Gasto total $=291840$ reales

- 18 trituradores fijos a 6 reales $=108$

- 50 espurgadores por término medio pagados a cuatro reales uno con otro $=200$

- Gasto diario en jornales $=308$ reales 
- Varas de almez, a 50 reales carga de 250 y desgaste de herramientas $=30$

- Conducción del agua y jornal de las dos caballerías con su arriero = 12

- $\quad$ Gasto diario total $=350$ reales

\section{Gastos generales relacionados con la fundición}

- Mano de obra, once y medio jornales de fundidores a nueve reales $=103,5$

- Mano de obra, once y medio ídem de ayudantes a seis reales $=69,00$

- Combustible, catorce cargas de atocha por día y por horno o sean 161 cargas, cuyo precio varía de dos y medio a tres reales carga; esto es de 402 a 483 reales. Apuntaré este último número por el mayor gasto del que no hago mérito en los hornos de leña $=483,00$

- Quiebras, crisoles (3), recipientes, tapaderas y alargaderas, siete reales tres maravedís por cada fundición o sea por las $23=163,00$

- Aceite, se dan dos onzas a los fundidores por operación o sean dos libras 14 onzas para las 23 a dos reales 12 maravedís libra, son $=6,34$

- Herramientas $=\ldots$

- $\quad$ Total $=824,84$ reales

\section{Resumen económico del coste de quintal producido}

- Laboreo, coste del quintal mineral bruto a 0,83000 reales arroba $=3,3400$ reales

- Preparación mecánica, costo de la quiebra y limpia del quintal del minero a punto de fundición a 0,4118 arroba $=1,6472$ reales

- Por el costo del mineral bruto necesario 2,05 quintales a 3,3400 quintales = 6,8470 reales

- Beneficio o destilación, costo del beneficio por quintal de azufre obtenido a 4,1440 arrobas $=16,5760$ reales

- Por el coste del minero limpio necesario, cinco quintales a 8,4942 quintales = 42,4710 reales

- Costo del quintal de azufre producido $=59,0470$ reales. 


\section{ANEXO 2. ESQUEMA CRONOLÓGICO DE LOS PRINCIPALES ACONTECIMIENTOS ACAECIDOS EN LAS MINAS}

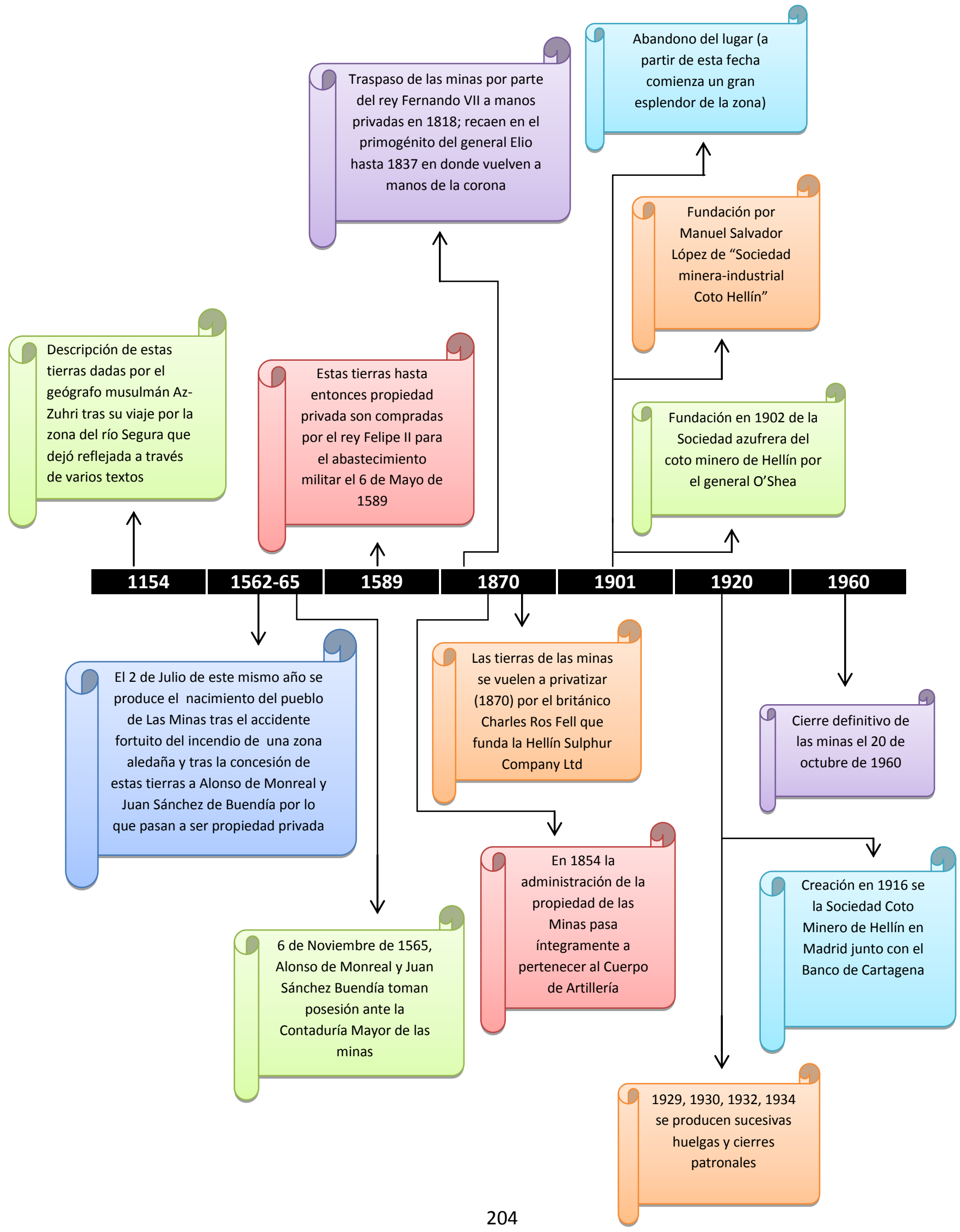


(c) Copyright Cristina Romera Tébar, 2014.

(C) Copyright GeoGraphos, 2014.

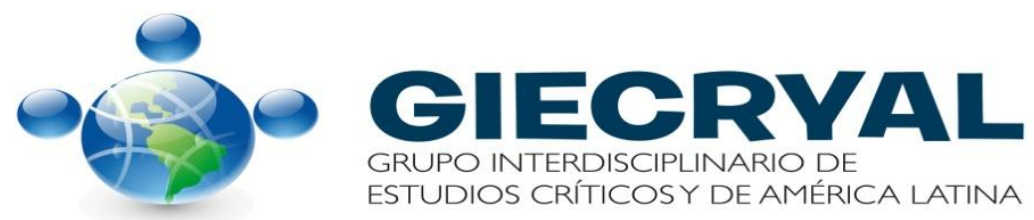

